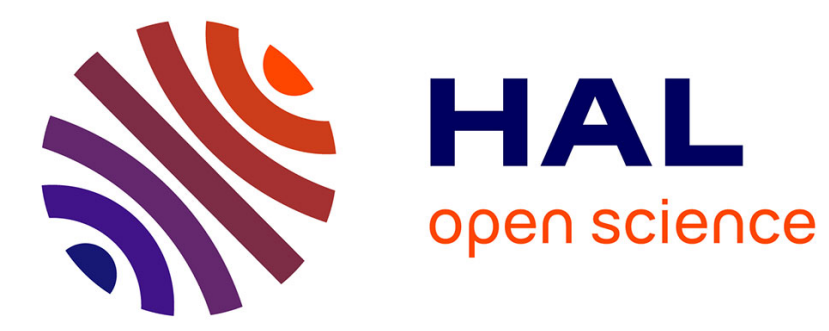

\title{
Short-Run Pain, Long-Run Gain: The Conditional Welfare Gains from International Financial Integration
}

Raouf Boucekkine, Giorgio Fabbri, Patrick A. Pintus

\section{To cite this version:}

Raouf Boucekkine, Giorgio Fabbri, Patrick A. Pintus. Short-Run Pain, Long-Run Gain: The Conditional Welfare Gains from International Financial Integration. 2016. halshs-00790569v6

\section{HAL Id: halshs-00790569 \\ https://shs.hal.science/halshs-00790569v6}

Preprint submitted on 29 Jun 2016

HAL is a multi-disciplinary open access archive for the deposit and dissemination of scientific research documents, whether they are published or not. The documents may come from teaching and research institutions in France or abroad, or from public or private research centers.
L'archive ouverte pluridisciplinaire HAL, est destinée au dépôt et à la diffusion de documents scientifiques de niveau recherche, publiés ou non, émanant des établissements d'enseignement et de recherche français ou étrangers, des laboratoires publics ou privés. 


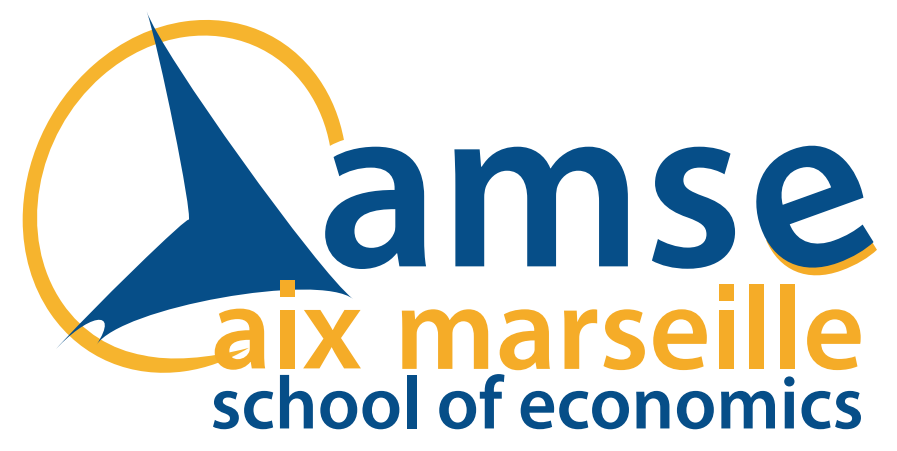

\section{Working Papers / Documents de travail}

Short-Run Pain, Long-Run Gain: The Conditional Welfare Gains from International Financial Integration

Raouf Boucekkine

Giorgio Fabbri

Patrick A. Pintus 


\title{
Short-Run Pain, Long-Run Gain: the Conditional Welfare Gains from International Financial Integration*
}

\author{
Raouf Boucekkine ${ }^{\dagger}$ \\ Giorgio Fabbri ${ }^{\ddagger}$ \\ Patrick A. Pintus ${ }^{\S}$
}

June 28, 2016

\begin{abstract}
This paper aims at clarifying the analytical conditions under which financial globalization originates welfare gains in a simple endogenous growth setting. We focus on an openeconomy $A K$ model in which the capital-deepening effect of financial globalization boosts growth in a in permanent but entails an entry cost in order to access international credit markets. We show that constrained borrowing triggers substantial welfare gains, even at small levels of international financial integration, provided that the autarkic growth rate is larger than the world interest rate. Such conditional welfare benefits boosted by stronger growth - long-run gain - arise in our preferred model without investment commitment and they range, relative to autarky, from about $2 \%$ in middle-income countries to about $13 \%$ in OECD-type countries under international financial integration. Sizeable benefits emerge despite the fact that consumption initially falls - short-run pain - which is however shown not to dwarf positive growth changes.

Keywords: International Financial Integration, Collateral-Constrained Borrowing, Welfare Gains, Endogenous Growth, Growth Breaks

Journal of Economic Literature Classification Numbers: F34, F43, O40
\end{abstract}

* This is a revised version of a very different paper first circulated under the title "Leapfrogging, Growth Reversals and Welfare". The authors would like to thank the Co-Editor, Tim Kehoe, as well as two referees for comments and suggestions that helped improving the paper, and Gadi Barlevy, Simon Board, Oded Galor, Jean Imbs, Omar Licandro as well as conference participants for feedback.

$\dagger$ Aix-Marseille University (Aix-Marseille School of Economics), CNRS \& EHESS. E-mail: raouf.boucekkine@univ-amu.fr.

¥ EPEE, Université d'Evry-Val-d'Essonne (TEPP, FR-CNRS 3126), Département d'Economie, 4 bd. François Mitterrand, 91025 Evry cedex, France. E-mail: giorgio.fabbri@uniparthenope.it.

$\S$ Banque de France, 41-1422 DEMFI-POMONE, 75049 Paris Cedex 01, France.E-mail: papintus@gmail.com. 


\section{Introduction}

Whether the capital-deepening effect of financial globalization generates welfare gains or losses is a concern that haunts academics and policymakers alike. According to the "textbook view", which is aptly summarized in Broner and Ventura [13], opening up capital accounts in a frictionless world should lead to larger investment, faster growth and ultimately welfare improvements. Increasingly, however, the recent theoretical literature is questioning such a rosy view and, more precisely, is predicting ambiguous effects of liberalization on welfare. To mention but a few recent contributions, Mendoza, Quadrini and Rios-Rull [34] show that financial globalization without financial development may result in adverse effects on social welfare and the distribution of wealth, Antràs and Caballero [3, 4] stress that long-run consumption may go either up or down relative to autarky depending on financial frictions, while Aoki, Benigno, and Kiyotaki [5] underline that different groups might gain or loose after liberalizing international asset transactions. Because most papers belonging to this literature assume that long-run growth is either nonexistent or exogenous, however, the question of whether or not welfare improves when international financial integration is growth-enhancing can hardly be addressed.

This paper aims at clarifying the conditions under which welfare gains arise when the main benefit from financial globalization is to boost growth in a permanent way, once an entry cost is paid in order to access international credit markets. Although a permanent effect on growth may seem a rather extreme property, it accords with recent papers that empirically document strong growth effects of financial globalization across space and time (e.g. Rancière, Tornell, and Westermann [37], Schularick and Steger [38]). On the other hand, the assumption that an autarkic country has to pay a sunk cost in order to access debt markets can be justified by some monitoring process that the international lender, e.g. a foreign bank, goes through in order to assess the level and quality of collateral in the prospective debtor country. In addition, one could think of other issuance costs attached to syndicated loans or bond issuances, such as disclosure-related costs, as well as bank and other legal fees. For simplicity, we assume that such a once-and-for-all entry cost is proportional to the initial capital stock, which turns out to be mathematically equivalent to the assumption that debt contracting does not lead to additional capital instantaneously but, in contrast, triggers a once-and-for-all transfer towards the rest of the world. Then capital accumulation and growth improve because of access to international debt market.

In line with the aforementioned literature, we focus on capital inflows as a potential source for financing domestic investment. In a simple $A K$ model with collateral-constrained borrowing, we show that substantial welfare gains materialize, even at small levels of financial integration. However, our analysis also underlines an important proviso to such a rosy view: only those countries enjoying an autarkic growth rate that is larger than the world interest rate benefit from limited borrowing. On the contrary, countries with autarkic growth rates that are much lower than the world interest rate potentially benefit from financial integration, but only if they have access to unrealistically high levels of borrowing. In this sense, the policy implications of our results are 
clear-cut: among the many possible courses of action, the best a policymaker can do to achieve high welfare is to ensure that the autarkic growth rate is larger than the world interest rate before opening up capital accounts. ${ }^{1}$

We derive our main results in two steps. We first use the most basic open-economy extension of the $A K$ model in which foreign debt is collateral-constrained to prevent default, as in Eaton and Gersovitz [22], Cohen and Sachs [18], Barro et al. [7] (see also, more recently, Aghion et al. [2], Devereux and Yetman [20] among others). We view this benchmark setting as a useful vehicle to carry intuition. Under the condition that the autarkic growth rate is larger than the world interest rate, we show that welfare gains, expressed as the compensating variation in consumption, are about $5 \%$ at low levels of international financial integration, with even larger gains at higher levels of indebtedness (see Table 1 below). Because borrowing more and investing more go hand in hand and boost growth rather mechanically in our framework, the conclusion that large welfare gains obtain may sound unsurprising. What makes our results far from obvious is that, in our open-economy setting, large welfare gains boosted by higher growth under international financial integration come together with a change in the consumption profile that does not favor welfare gains. More precisely, we show that significant welfare benefits originate from a positive growth effect - the growth rate increases with financial integration - that conflicts with a negative level effect on initial consumption - initial consumption falls under financial integration. That is, optimal consumption initially falls when the economy becomes financially integrated and then grows faster, compared to autarky (see figure 1 below). ${ }^{2}$ Key to the latter result is of course our assumption that accessing international debt market entails a once-and-for-all sunk cost.

The conclusion that initial consumption has to fall when the economy switches from autarky to financial integration (or, similarly, if it opts for deepening financial integration) captures the broader view that financial globalization may lead to long-run gain at the expense of short-run pain (e.g. Kaminsky and Schmukler [29]). In our framework, the short-run pain comes from two effects that the newly integrated economy faces. First, access to the debt market initially and then servicing interest payments on the debt cost resources. Second, leveraged borrowing means that the only way to borrow more is to invest more, which accelerates investment in the financially integrated economy because growth is now higher. Both effects combine to curtail initial consumption - a short-run pain indeed. We show that the welfare loss associated with the fall in consumption is in fact large. This sets the stage for assessing the robustness of this preliminary finding in our preferred model of foreign borrowing.

Our preferred model relaxes the assumption of investment commitment and it assumes that new loans depend on realized investment - as opposed to planned investment - essentially because past levels of investment can be verified using balance sheets. In such a setting, which nests the basic model as a special case, a no-commitment delay is introduced (as in Cohen and Sachs [18],

\footnotetext{
${ }^{1}$ For example by investing in public infrastructures, as in a Barro-type version of the $A K$ model.

${ }^{2}$ In contrast, such a consumption tilting has been shown by Barlevy [6] to dwarf the welfare gains from removing business cycles in a closed-economy version of the $A K$ model.
} 
Boucekkine and Pintus [11]). Although many trivial types of informational lags could potentially justify such a delay, our favorite explanation comes quite naturally from ruling out investment commitment by borrowers when the debt contract is decided upon by foreign lenders. To put it simply, we assume that while borrowers cannot borrow against the promise to invest, they can borrow, however, if they document that they have invested in the past. As described in the next section, such a delay may be interpreted as negatively related to the borrower's reputation for not being myopic. Several reasons account for why we think that the model without investment commitment is important. That investment commitment is hardly credible in an international context seems to be a reasonable assumption because there is no such thing as an international law court to which lenders can resort in case promised investment does not materialize. In addition, it is arguably harder for international lenders to mitigate the effect of imperfect information about whether or not (foreign) borrowers are myopic. ${ }^{3}$ International creditors then have to rely on limited information to choose how much to lend, and past investment is arguably a very relevant piece of information.

The no-commitment delay makes the optimal control problem non-standard, as shown in Appendix A.2 where we derive optimal consumption and show that it jumps to the balanced growth path, as in a closed-economy $A K$ model. This characterization of optimal consumption without investment commitment is key to enable us to study welfare, just as in our simplest setting with investment commitment, as determined by both a growth-enhancing effect and a level effect on initial consumption. Beside the ones stated above, another reason why this more general model is also an important extension to consider is because it is biased towards smaller welfare gains due to two new effects. First, the no-commitment delay hampers long-run growth, which is consistent with the broader view that financial market imperfections and enforcement problems are bad for growth. Second, the model then predicts that growth breaks materialize, which accord with the evidence about most countries provided by Hausmann, Pritchett and Rodrik [25], Jones and Olken [28], Cuberes and Jerzmanowski [19]. Because such documented growth volatility is often thought to be a potential source of welfare losses under financial integration (e.g. Bussière and Fratzscher [16]), we ask whether having growth breaks as a prediction of our model still allows for large welfare gains. We show that the answer is positive: even developing countries that face a tight borrowing constraint enjoy significant welfare gains from financial integration without investment commitment, provided that they grow fast enough under autarky. Another feature of our preferred model is that welfare also depends on the entire historical growth path, and not only on the initial capital stock as in a standard $A K$ model, as developed further in Appendix B which exposes additional results on leapfrogging and growth breaks.

The main quantitative implications arising in our preferred model are as follows (see Table 3 below). Relative to autarky, welfare gains now range from about $2 \%$ in (tightly credit-constrained) middle-income countries to about $13 \%$ in (less constrained) OECD countries under international

\footnotetext{
${ }^{3}$ For game-theoretic foundations of cooperative behavior that are relevant in our setting, see e.g. Gosh and Ray [24] and the references therein.
} 
financial integration. Such large gains occur despite both a negative level effect on initial consumption - which again falls under financial integration - and a negative impact of the no-commitment delay on the growth rate. A policy implication of our analysis is that debt-reducing policies (implemented, for example, through strict controls of capital inflows) generate welfare losses that range from $1 \%$ to $12 \%$ depending of how abrupt the policy is.

Related Literature: As mentioned above, many papers in the literature about the welfare impact of financial integration assume that growth is exogenous. In such a framework, welfare gains are tightly linked to the fact that international integration accelerates convergence (see Barro et al. [7]). This means that welfare gains originate from transitional dynamics and, therefore, that any growth effect is necessarily temporary. This is for example the case in Antràs and Caballero [4], where growth vanishes in the long-run and both the level effect and the growth effect on consumption are ambiguous in the short-run. Although few related papers study welfare gains in an endogenous growth setting, to our knowledge no paper focuses on capital-deepening under borrowing constraints. For example, Epaulard and Pommeret [23] extend the literature on international risk sharing (Obsteld [35], Acemoglu and Zilibotti [1], van Wincoop [40] and many others) but they abstract from borrowing limits - and they assume exogenous growth volatility - in contrast with our paper. Hoxha, Kalemli-Ozcan and Vollrath [27] show that sizeable welfare gains from financial integration arise in an exogenous-growth setting with imperfectly substitutable capital goods, even when capital flows in only gradually. Interestingly, because their model nests both the neo-classical model and the $A K$ model, Hoxha, Kalemli-Ozcan and Vollrath [27] make clear why welfare gains go to infinity in the limit, absent borrowing constraints, when the model converges to the $A K$ setting. In contrast, welfare gains are finite - and reasonable - in our $A K$ formulation with constrained borrowing. ${ }^{4}$

Our main contribution is to show that endogenous growth leads to a very different but clearcut configuration, compared to exogenous growth, first by making clear why sustained growth gains are key to generate sizeable welfare improvements, and second by showing that even when financial globalization boosts growth in a permanent way, how welfare changes is far from obvious. In addition to the positive effect of international financial integration on growth, as underlined above our benchmark $A K$ model also predicts a negative effect on initial consumption that goes against welfare gains and is absent in the literature focusing on exogenous growth. An open question in our context, which we answer positively, is then whether or not welfare gains materialize in the first place. When they do, welfare benefits from international financial integration obtained in our framework rely on moderate capital inflows. For instance, an increase in welfare of about $2 \%$ occurs when the economy is lent about $25 \%$ of its capital stock. Our results also arguably complement Rancière et al. [37] by providing a simple model in which financial integration generates both volatility in output growth in the short-run combined with higher growth in the long-run, as well

\footnotetext{
${ }^{4}$ Bretscher and Steger [12] also study related issues but they abstract from the optimal intertemporal allocation of consumption.
} 
as substantial welfare gains. Finally, our main conclusion that welfare gains are conditional does not disagree with the vast empirical literature indicating that the impact of financial globalization varies across space (see e.g. the surveys by Kose et al. [32], Obstfeld [36]) and time (see e.g. Schularick and Steger [38]).

The paper is organized as follows. Section 2 sets the stage by presenting the model. We then proceed in section 3 to derive the conditions under which large welfare gains arise, both with investment commitment and without. Section 4 presents numerical results while section 5 gathers concluding remarks. Finally proofs and additionl results are exposed in the appendix.

\section{A Small-Open Economy $A K$ Model without Investment Commitment}

We solve for the allocation chosen by a planner in an extension of the small open-economy version of the $A K$ model without investment commitment. The economy produces tradeable output $Y$ according to a linear technology, $Y=A K$, where $K>0$ is the stock of capital, $A>0$ is total factor productivity. Whereas output is tradeable, inputs are not. ${ }^{5}$ The Ramsey households are infinitely-long lived and derive utility according to the following formulation:

$$
\int_{0}^{\infty} e^{-\rho t} \frac{C(t)^{1-\sigma}-1}{1-\sigma} d t
$$

where $C>0$ is consumption, $1 / \sigma>0$ is the elasticity of intertemporal substitution, and $\rho>0$ is the discount rate. The economy borrows from the rest of the world and, accordingly, its budget constraint is:

$$
\dot{K}(t)-\dot{D}(t)=A K(t)-\delta K(t)-r D(t)-C(t),
$$

where $r \geq 0$ is the world interest rate, $\delta \geq 0$ is the rate of capital depreciation, and $D$ is the stock of net foreign debt. The initial stocks $K(0)>0, D(0)$ are given to the households.

We focus on collateral-constrained borrowing without commitment to investment and, following Boucekkine and Pintus [11], we posit that the creditor lends up to some fraction of the past value of collateral $\lambda K(t-\tau)$, for some exogenous delay $\tau \geq 0$ and credit multiplier $\lambda>0$. This formulation of the endogenous debt constraint faced by a small open economy is meant to capture the fact that foreign lenders condition new loans on realized investment (as opposed to expected investment when $\tau=0$ ). This feature seems a not too unrealistic description of the real world, where borrowers cannot commit in a credible way to an investment level when the lending contract with foreign financial intermediaries is decided upon. As a consequence, lenders resort to the most recent legal documents (e.g., balance sheets) to assess both the value of collateral and how much can be safely lent to a foreign firm. This entails an informational lag that we measure by the no-commitment delay

\footnotetext{
${ }^{5}$ Our results are virtually unchanged under capital mobility, which sets the net marginal product of capital equal to the world interest rate.
} 
$\tau$. A useful interpretation of the delay is that it is inversely related to the borrower's reputation. That is, the larger $\tau$, the less reliable the borrower and the more likely he will not repay all his debt. When $\tau$ is large, therefore, the farther into the borrower's past the lender goes to scrutinize the debtor's investment path and collateral worthiness.

Assumption 2.1 The open economy is not more patient that the rest of the world, that is, $\rho \geq r$. Foreign borrowing is subject to a limit such that $\lambda K(t-\tau) \geq D(t)$, with the credit multiplier $\lambda \geq 0$ and the no-commitment delay $\tau \geq 0$. In addition, the autarkic economy has to pay a once-and-forall entry cost $r \lambda K(-\tau)$ in order to have permanent access to international credit markets.

The main motivation behind the entry cost is that foreign lenders need to assess the initial level and quality of collateral that the autarkic economy possesses prior to financial integration. All costs related to such a process are fully paid by the candidate country so that the analysis unfolds as if the initial level of debt is $D(0)=\lambda K(-\tau)$, that is, the entry sunk cost is a transfer from the opening country to the rest of the world that equals $r \lambda K(-\tau) .{ }^{6}$ In mathematical terms, this means that the level of debt jumps at $t=0$ from 0 to a positive value $\lambda K(-\tau)$. In our one-good model setting this debt path should correspond, in absence of any friction, to a jump up in the capital stock. We suppose instead an entry cost that acts in the following way: the debt contracted at time 0 does not transform at time 0 into additional capital goods but translates into a transfer abroad. After $t=0$, the benefits from integration and borrowing materialize in terms of capital accumulation and growth. This corresponds to our choice of considering the initial level of capital in the integrated economy equal to the level of capital before integration, and the initial debt level equal to $\lambda$ times the level of capital before integration, that is, $D(0)=\lambda K(-\tau)$. It is worth mentioning that this entry cost is small as long as the interest rate $r$ is small and that its presence is key to explain the contrasted results about how financial integration affects welfare that we obtain below. ${ }^{7}$.

The following statement underlines both that there generically does not exist a permanent regime such that the debt constraint in Assumption 2.1 is slack and that, in contrast, the debt constraint binds at all dates under some simple condition.

\section{Proposition 2.1 (Binding Debt Limit)}

Under Assumption 2.1, there does not exist a permanent regime such that $\lambda K(t-\tau)>D(t)$ at all dates $t \geq 0$ whenever $A-\delta \neq r$. In addition, the debt constraint binds, that is $D(t)=\lambda K(t-\tau)$, for all $t \geq 0$ if $A-\delta>r$.

Proof: See Appendix A.1.

The first part of Proposition 2.1 implies that the debt constraint cannot always slack when $A-\delta \neq r$. This condition is easy to interpret: as noted by Cohen and Sachs [18], absent the debt constraint, the economy would like to invest or disinvest at infinite rate depending on whether $A-\delta$

\footnotetext{
${ }^{6}$ Assuming linear monitoring cost is common in the literature, see e.g. Carlstrom, Fuerst and Paustian [17].

${ }^{7}$ We thank very much a referee for drawing our attention to this last point.
} 
is larger or smaller than $r$ and this in turn implies that the economy's net asset position would go to either minus infinity or plus infinity. Since our goal is to study the capital deepening effect of financial globalization, we model the economy as a net debtor with respect to the rest of the world and we follow Cohen and Sachs [18] by assuming that $A-\delta>r$, in which case the debt constraint always binds according to the second part of Proposition 2.1. ${ }^{8}$

Because the debt constraint always binds, one can plug the expression of $D(t)=\lambda K(t-\tau)$ into the budget constraint (2), which gives:

$$
\dot{K}(t)=\lambda \dot{K}(t-\tau)+\varepsilon K(t)-r \lambda K(t-\tau)-C(t),
$$

where $\varepsilon \equiv A-\delta$. The problem solved by the planner is then to maximize (1) subject to (3), which turns out to be a non-standard optimal control problem that we solve using techniques developed in Boucekkine, Fabbri and Pintus [10]. More precisely, (3) is not an ordinary differential equation due to the delayed terms $K(t-\tau)$ and $\dot{K}(t-\tau)$. Because of these two terms, the budget constraint (3) falls into the class of non-autonomous, linear Neutral delay Differential Equations (NDE for short, see Bellman and Cooke [8, chap. 6]). Both delayed terms reflect the decisive role of historical conditions in determining the growth path followed by the economy without investment commitment. In contrast to the standard $A K$ setting in which the initial capital stock $K_{0}$ is the only data required to determine the optimal path, here the whole initial history (captured by an initial function $K_{I}(t)$ for all $\left.t \in[-\tau, 0]\right)$ is needed. This latter feature alone implies that one faces an infinite dimensional (functional) problem and that, unlike standard dynamical systems, infinitely many roots govern stability. As remarked in Boucekkine, Fabbri and Pintus [10], where the technical details of the analysis are laid out ${ }^{9}$, there are very few papers dealing with this type of maximization problems. ${ }^{10}$

\section{Proposition 2.2 (Optimal Consumption)}

Under Assumption 2.1, suppose that $A-\delta-r>0$ and $1 \geq \lambda$. Then the optimal consumption profile is given by $C(t) \equiv C_{0} e^{g t}$, where $g=(\xi-\rho) / \sigma$ is the growth rate, initial consumption is:

$$
C_{0}=\left\{\frac{\rho-(1-\sigma) \xi}{\sigma}\right\}\left\{K_{I}(0)-\lambda K_{I}(-\tau)+(\xi-\varepsilon) \int_{-\tau}^{0} e^{-\xi s} K_{I}(s) d s\right\}
$$

$K_{I}(t)$ is the initial function that is given for all $t \in[-\tau, 0], \xi$ is the unique positive real root of the characteristic equation $Q(x) \equiv x-\lambda x e^{-x \tau}-\varepsilon+r \lambda e^{-x \tau}=0$ with $\varepsilon \equiv A-\delta$ and $\rho>(1-\sigma) \xi$.

\footnotetext{
${ }^{8}$ Cohen and Sachs [18] introduce adjustment costs to ensure finite investment, which we do not need since there is a limit on how much the economy is able to borrow and, hence, to invest. We conjecture that adding adjustment costs to our analysis would delay the date at which the economy switches to the regime with binding debt constraint.

${ }^{9}$ More precisely, the techniques used in Boucekkine, Fabbri and Pintus [10] rely on dynamic programming developed by Bensoussan et al. [9] for infinite dimensional spaces.

${ }^{10}$ The simpler case of constant savings rate is analyzed in Boucekkine and Pintus [11], in which we study the stability of the associated (autonomous) NDE.
} 
Proof: See Appendix A.2.

The general setting under which optimal consumption behaves as described in Proposition 2.2 has two important benchmarks. (i) Under autarky, $\lambda=0$ so that the economy does not borrow and one goes back to the standard closed-economy $A K$ model such that the autarkic growth rate is $g_{a} \equiv(\varepsilon-\rho) / \sigma$, which is assumed to be positive. This is because the characteristic function $Q$ in Proposition 2.2 is then a first-order polynomial with a unique root $\xi=\varepsilon$. (ii) Under financial integration with investment commitment, one has $\lambda>0=\tau$ and there still exists a unique balanced-growth path (BGP for short), as in the autarkic case, such that $g=(\xi-\rho) / \sigma>g_{a}$, with $\xi=(\varepsilon-r \lambda) /(1-\lambda)$. Note that in both benchmarks, there is no transitional dynamics and the economy jumps at the initial date on the BGP (see section 3.1). This is in contrast with what happens without investment commitment (when $\tau>0$, however small): although consumption jumps to its optimal path described in Proposition 2.2, the dynamics of capital follows the NDE (3) and converges only asymptotically towards the BGP, and so do output and investment (see section $3.2)$.

From Proposition 2.2, it is straightforward to derive the comparative statics properties of the BGP growth rate and, in particular, that $d g / d \lambda>0>d g / d \tau$. This implies that both more borrowing (that is, a larger $\lambda$ ) and better reputation (that is, a lower $\tau$ ) boosts growth. This captures the view that international financial integration is good for growth. In addition, welfare depends on an additional level effect (through initial consumption $C_{0}$ ) and Proposition 2.2 shows that it depends not only on $\lambda$ and $\tau$, but also on the historical growth path, as evident from direct inspection of (4) in which the initial function $K_{I}(s)$ matters. The less trivial comparative statics of $C_{0}$ is examined in the next sections.

Let us now note that the above results about solving for optimal consumption, while technically demanding, are rewarding because they enable us to study welfare in a simple way when $\tau \geq 0$. In particular, the fact that, just as in a standard $A K$ model, consumption jumps at $t=0$ to the BGP greatly simplifies the analysis because there is no transitional dynamics of consumption (in contrast, remember that the capital stock that solves the NDE (3) is shown to converge asymptotically to the BGP). Therefore, welfare changes are expected to depend on how parameters (most notably the delay $\tau$ and the credit multiplier $\lambda$ ) affect both the level of initial consumption and the growth rate. In other words, it is useful to think about the welfare impact of international financial integration as the combination of both a growth effect (through the BGP growth rate $g$ ) and a level effect (through the initial consumption $C_{0}$ ). Such a negative level effect conflicting with the positive growth effect is typically absent from the literature about the impact of international financial integration. In our context, this makes the overall impact on welfare ambiguous.

Before moving on, it is perhaps instructive to ask whether or not results differ in the endogenousgrowth model that we solve and in exogenous-growth models. The property that consumption falls when the small-open economy integrates may or may not hold in optimal growth models with diminishing returns to capital accumulation and constrained borrowing, depending on parameter values. 
For instance, under exogenous growth and a constant savings rate, consumption is proportional to output and does not fall when the economy opens up. Besides the obvious limitation that such models cannot account for sustained growth, another complication that obscures the analysis is that only numerical results can be derived, in contrast with the full analysis of the endogenous-growth model that we now develop. ${ }^{11}$

\section{Welfare Gains from International Financial Integration}

\subsection{The Benchmark Case with Investment Commitment}

The simplest benchmark case against which we first compare autarky happens when $\lambda>0=\tau$, which leads to a standard open-economy version of the $A K$ model with investment commitment. Because new debt flows $\dot{D}$ are matched with the promise to invest more (by the amount $\lambda \dot{K}$ ), this is tantamount to assuming investment commitment. The purpose of this section is to show that, in such a setting, international financial integration may generate large welfare gains. This may come as a surprise in view of the fact that the optimal consumption profile tilts in a counterclockwise fashion, as depicted in figure 1, which reflects that both a positive growth effect and a negative level effect are triggered by international financial integration.

Figure 1 gives a preview of our results that financial integration boosts growth at the cost of reducing initial consumption. More precisely, figure 1 graphs the log of consumption (that is, $\ln \left\{C_{0}\right\}+g t$ ) and compares autarky (when $\lambda=0$ ) with financial integration $(\lambda>0)$. Financial openness tilts optimal consumption upward because it allows more borrowing, hence more investment, which boosts the growth rate of consumption at the expense of lower consumption initially. When $\lambda>0$, the open-economy representative household starts at $t=0$ with a lower consumption level $C_{0}^{o}<C_{0}^{a}$, where $C_{0}^{a}$ is initial consumption under autarky $(\lambda=0)$, and enjoys higher consumption growth from $t=0 \mathrm{on}$. It is worth mentioning that the configuration depicted in figure 1 has been shown to imply only trivial welfare gains from removing business cycles in a standard $A K$ model. More precisely, Barlevy [6] proves that large welfare gains from eliminating volatility arise when, in contrast, higher growth comes together with constant initial consumption (see figure 1 in Barlevy [6, p. 965]). That is, when the growth effect is positive while the level effect is nil. In contrast, we now show that international financial integration generates welfare gains that are of the same order of magnitude (and even larger) than those obtained by Barlevy [6], despite the presence of a negative level effect that tilts consumption as depicted in figure 1. In addition, our analysis also stresses an important proviso to such a rosy view: as one can guess by direct inspection of figure 1, welfare goes up only if the growth effect dominates the level effect, which turns out to be the case only if the autarkic growth rate is large enough, as we now show.

\footnotetext{
${ }^{11}$ Another - hardly noticed - result happens to hold in deterministic exogenous-growth models of a small-open economy. It has to do with the fact that steady-state consumption is lower under financial integration, which triggers default when the economy is close enough to its steady state.
} 
Figure 1: the consumption tilting effect of international financial integration. Solid line: autarky $(\lambda=0)$; dashed line: financial integration $(\lambda>0)$

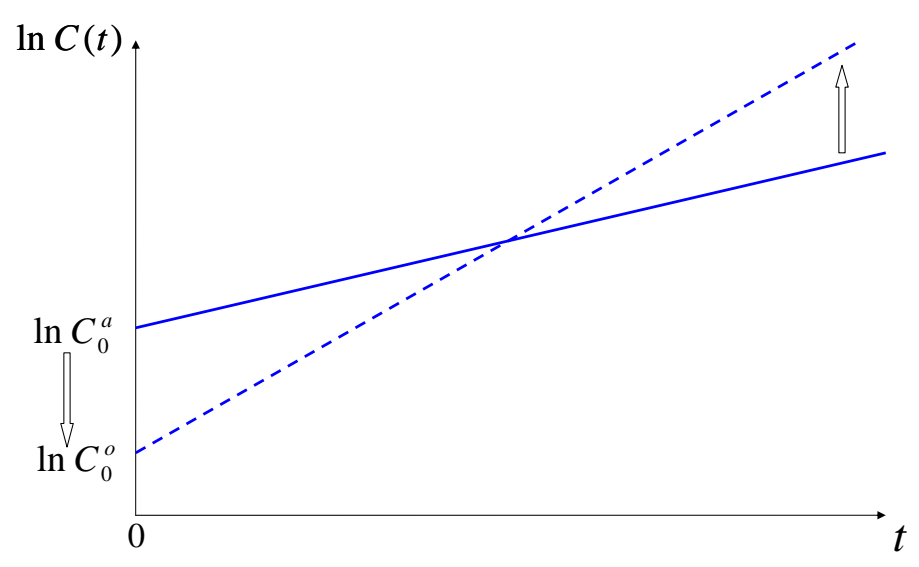

In the open-economy version of the standard $A K$ model with investment commitment, the corresponding growth rate is given by $g=(\xi-\rho) / \sigma>g_{a}$ with $\xi=(\varepsilon-r \lambda) /(1-\lambda)$. Under the assumptions of Proposition 2.2 and consistent with our remarks above, it turns out that $g$ is an increasing function of $\lambda$ whereas, under mild assumptions, $C_{0}$ is a decreasing function of $\lambda$.

\section{Proposition 3.1 (Growth and Level Effects with Investment Commitment)}

Under the assumptions of Proposition 2.2 and investment commitment (that is, $\tau=0$ ), the nodelay growth rate is given by $g=(\xi-\rho) / \sigma>g_{a}$, with $\xi=(\varepsilon-r \lambda) /(1-\lambda)$ and $d g / d \lambda>0$. In addition, initial consumption $C_{0}=(\rho-(1-\sigma) \xi)(1-\lambda) K_{I}(0) / \sigma$ is then such that $d C_{0} / d \lambda<0$ when $\sigma \geq 1$ (and provided that $\sigma>1-\rho / r$ if $\sigma<1$ ). That is, foreign borrowing boosts growth and reduces initial consumption.

Proof: see appendix A.3.

Proposition 3.1 shows that increasing the credit multiplier $\lambda$ has opposite growth and level effects, which accords with intuition. Under investment commitment, relaxing the credit constraint gives larger incentives to accumulate capital, which boosts growth. However, larger incentives to invest also mean that households are willing to consume less initially, knowing that consumption will grow 
faster when $\lambda$ is higher (see figure 1). ${ }^{12}$ This happens, for instance, under the mild requirement that intertemporal substitution in consumption $1 / \sigma$ is less than unity. Under the assumption that the economy is not more patient than the lenders (that is, $\rho \geq r$ ), then $C_{0}$ falls when $\lambda$ increases for all positive values of $\sigma$. By rewriting the NDE governing the dynamics when $\tau=0$ as:

$$
(1-\lambda) \dot{K}(t)+r \lambda K(t)=\varepsilon K(t)-C(t)
$$

it is not difficult to see that the fall in initial consumption comes from two effects that the newly integrated economy faces. First, when $\lambda>0$, a new term $r \lambda K$ stands for the fact that repaying debt costs some resources. Second, leveraged borrowing means that the only way to borrow more is to promise to invest more, which accelerates investment $(1-\lambda) \dot{K}$ in the financially integrated economy because the growth rate is now higher. Both effects combine to curtail initial consumption - a short-run pain indeed. We now show under logarithmic utility that the growth effect dominates so that welfare is an increasing function of $\lambda$ under some condition that we now derive.

Under logarithmic utility, welfare is given by $W \equiv \int_{0}^{+\infty} e^{-\rho t} \ln \{C(t)\} d t$. Using $C(t)=C_{0} e^{g t}$ with $g \equiv \xi-\rho$ and $\xi=(\varepsilon-r \lambda) /(1-\lambda)$, one gets by straight integration by parts that:

$$
W=\frac{1}{\rho}\left\{\ln \left\{C_{0}\right\}+\frac{\xi-\rho}{\rho}\right\}
$$

We follow standard practice by computing the compensating variation in consumption, denoted $\psi$ below, that is required to achieve equal welfare both in autarky and under financial integration, depending on $\lambda$ which is our measure of financial openness. Under logarithmic utility, straightforward computations deliver that the compensating variation in consumption is given by:

$$
\psi \equiv \frac{C_{0}}{C_{0}^{a}}\left\{e^{\left(g-g_{a}\right) / \rho}\right\}-1
$$

The following proposition establishes that, under investment commitment, welfare gains materialize at all levels of financial integration, provided that the autarkic growth rate is larger than the world interest rate.

\section{Proposition 3.2 (Conditional Welfare Gains and Investment Commitment)}

Under the assumptions of Proposition 3.1 and logarithmic utility (that is, $\sigma=1$ ), $d W / d \lambda>0$ if and only if $g>r$, or equivalently, $\lambda>\underline{\lambda} \equiv\left(r-g_{a}\right) / \rho$, where $g_{a} \equiv A-\delta-\rho$ is the autarkic growth rate. That is, foreign borrowing improves welfare if and only the growth rate is larger than the world interest rate. It follows that two cases occur:

(i) if $g_{a} \geq r$, then $d W / d \lambda>0$ for all values of $\lambda>0$. That is, foreign borrowing improves welfare for all levels of the credit multiplier if the autarkic groth rate is larger than the world interest rate.

\footnotetext{
${ }^{12}$ It is important to notice that the "short-run pain, long-run gain" trade-off arising in our $A K$ economy does not hinge on dynamic inefficiency as in exogenous growth models. In addition, $C_{0}$ falls after integration also when the entry cost is arbitrarily small provided that $\rho \geq r$.
} 
(ii) if $r>g_{a}>r-\rho$, then $d W / d \lambda>0$ if and only if $\lambda>\underline{\lambda}$. It follows that foreign borrowing improves welfare if and only if $\lambda>\lambda_{c}$, where $\lambda_{c}>\underline{\lambda}$ is the unique positive solution to $\lambda(\varepsilon-r)=$ $-\rho(1-\lambda) \ln (1-\lambda)$.

Proof: see appendix A.3.

The conditions that $g>r$ is intuitive, as it states that international financial integration is good for welfare provided that the economy is productive enough to afford borrowing, given the world interest rate. In addition to the fact that the growth rate is an increasing of the credit multiplier (see Proposition 3.1), it follows that two cases occur, depending on whether the autarkic growth rate is or is not larger than the world interest rate. In case $(i), g_{a}>r$ so that $g>r$ for all $\lambda$ 's. In other words, if the autarkic economy was growing fast enough before it financially integrates, then its welfare increases with foreign borrowing at all levels of the debt-to-output ratio. The obvious interpretation of this proviso is that international financial integration is good for welfare only if growth-enhancing institutions (e.g. high quality governance, efficient domestic financial markets) are already in place under autarky. However, whenever $g_{a}<r$ as in case (ii) of Proposition 3.2, financial integration improves welfare only if $\lambda$ is large enough. That is, a threshold effect materializes, as shown in figure 2 because the growth effect has to be large enough to compensate for the negative effect in initial consumption. Of course, a country with $\lambda<\lambda_{c}$ would choose autarky over financial integration so that potential welfare losses would never materialize, as depicted in Figure 2. Note that the larger the difference $r-g_{a}$, the larger the thresholds $\underline{\lambda}$ and $\lambda_{c}$.

In summary, it follows from Proposition 3.2 that both in case $(i)$ and when $\lambda>\lambda_{c}$ in case $(i i)$, welfare gains arise because the growth rate $g$ is larger than the world interest rate $r$, which more than compensates for the fall in initial consumption $C_{0}$. One interpretation of this fact is that welfare gains from financial globalization materialize only if the economy is productive enough to afford borrowing at the given world interest rate. It is perhaps useful at this stage to summarize the main findings reported in the previous propositions. In the benchmark case of logarithmic utility, welfare gains obtain only if the growth effect is positive. If the assumption that $A-\delta>r$ is violated, then the growth rate falls when $\lambda$ increases so that both the level effect and the growth effect are negative. In that case, international financial integration does not trigger welfare gains for any $\lambda$ 's and a benevolent planner would opt for staying autarkic. If, on the contrary, the economy is productive enough to ensure that $A-\delta>r$, then the growth effect becomes positive and the country's rate of time preference is important as well to determine whether or not welfare gains materialize. If $\rho$ is small enough to ensure that $g_{a} \equiv A-\delta-\rho>r$, that is, if the economy is patient enough, then welfare gains obtain for all $\lambda$ 's. This means that, under such a condition, the growth effect always dominates the level effect. Therefore, provided that the autarkic economy grows fast enough, financial integration is good for welfare. If, however, autarkic growth is weaker (that is, if $r>g_{a}$ ), then welfare improves only of the economy can borrow enough in international credit markets (that is, if $\lambda>\lambda_{c}$ ). Such a threshold effect occurs because the growth effect is first dominated by the level effect at small levels of international financial integration, but then become 
Figure 2: the welfare gains from international financial integration. Threshold effect under case (ii) of Proposition 3.2

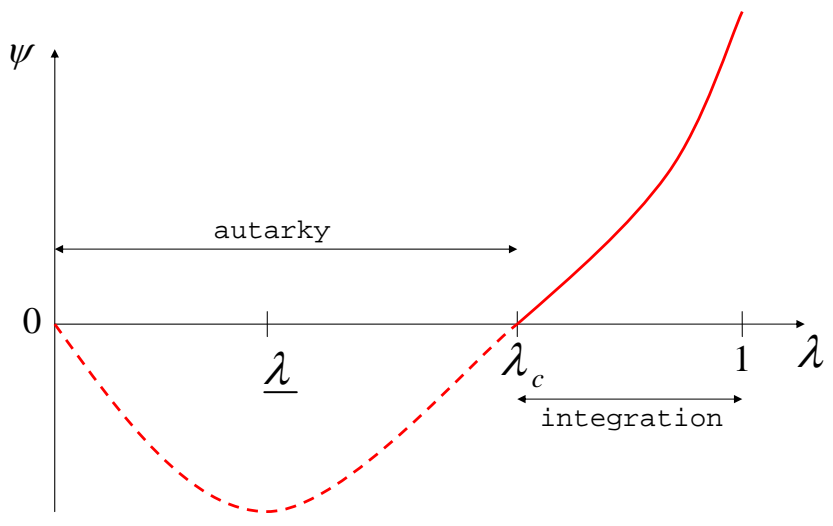

dominant when $\lambda>\underline{\lambda}$.

\subsection{The Case with No-Investment-Commitment Delay}

This section shows that foreign borrowing generates substantial welfare gains provided that the autarkic economy is growing faster than the world interest rate. The next sections show that, under the same proviso, such a result is robust to relaxing the assumption of investment commitment. Ruling out investment commitment is arguably more realistic but it is also a much more conservative assumption because it dampens welfare gains through two new effects. First, as shown above, the no-commitment delay reduces the BGP growth rate at all levels of $\lambda$, so that the positive growth effect is now reduced. The numerical examples below show that small delays dampen growth by a significant margin. Second, the model without investment commitment predicts growth breaks that accord with the empirical evidence, but do not occur under investment commitment. Similar to what happens with a constant savings rate (Boucekkine and Pintus [11]), Appendix B below shows that growth breaks and growth reversals occur in the optimal growth setting. Absent growth volatility, as in the above analysis with investment commitment, one may therefore argue that the results are strongly biased towards large welfare gains from financial integration, and we have seen above that they may be substantial when $\lambda$ is large. We now show that even though they are reduced, welfare gains still remain large without investment commitment, although this assumption 
both dampens growth and generates growth volatility in capital and output. A first necessary step is to study how the no-commitment delay $\tau$ affects growth and welfare, for a given $\lambda$.

The purpose of this section is to derive analytical results about welfare under logarithmic utility and with delays that are arbitrarily close to zero. Recall that we denote $K_{I}(t)$ the initial function defined for all $t \in[-\tau, 0]$. Then using the expression of the initial consumption level in equation (4), we now show that, for small delays, $C_{0}$ is an increasing function of the delay $\tau$.

\section{Lemma 3.1 (Small Delay and the Initial Consumption Level)}

Define $K_{I}(t)>0$ for all $t \in[-\tau, 0]$ as the initial function and $\mu \equiv \dot{K}_{I}(0) / K_{I}(0)$. Under the assumptions of Proposition 2.2, if in addition $\mu>\underline{\mu}$, with $\underline{\mu} \equiv(r-\varepsilon) /(1-\lambda)<0$, and utility is logarithmic $(\sigma=1)$, then $d C_{0} / d \tau>0$ at $\tau=0$.

That is, small no-commitment delays increase the optimal initial consumption level.

Proof: see appendix A.4.

From Lemma 3.1 follows the fact that the no-commitment delay has an ambiguous effect on welfare. This is because the delay has two opposite effects on the growth rate and on the initial level of consumption. On the one hand, there is a negative growth effect: increasing $\tau$ from zero reduces the growth rate $g=\xi-\rho$ (because it decreases the positive characteristic root $\xi$ ). In a growing economy, the higher the delay, the more severe the debt constraint, hence the lower the growth rate. On the other hand, there is a positive level effect: a positive $\tau$ tends to increase the initial consumption level that is optimally chosen by the infinitely-lived household (as shown in Lemma 3.1 under the mild requirement that the economy is not declining too fast initially, that is, if $\mu>\mu$ ). This is because under the prospect of slower consumption growth, it is optimal for households to increase their initial level of consumption so as to enjoy more consumption in initial periods.

Therefore, when the no-commitment delay increases from zero, a larger $C_{0}$ improves welfare whereas a lower $g$ has the opposite impact. Compared to figure 1, which describes the impact of increasing $\lambda$ from zero, consumption tilts downward when $\tau$ increases from zero. It perhaps helps intuition to note that a similar trade-off arises in the standard $A K$ model under autarky (that is, when $\lambda=0$ ) when the discount rate $\rho$ is made to increase. It can easily be shown that, ceteris paribus, a larger $\rho$ translates into slower growth but a larger initial level of consumption so that its impact on welfare is ambiguous a priori. Here also, slower growth provides households with stronger incentives to consume more initially, so that a similar trade-off arises and has an ambiguous effect on welfare. In summary, both the discount rate and the delay affect the incentives to accumulate capital in the same way: both larger $\rho$ 's and larger $\tau$ 's mean lower incentives to accumulate, which translate into lower $g$ 's but larger $C_{0}$ 's. In the former case, this is because households are more impatient while, in the latter case, it is because of a tighter borrowing constraint.

We now show that the short-run effect dominates the long-run effect, so that welfare increases when the delay goes up from zero, if and only if the initial growth rate $\mu$ is positive and large 
enough.

\section{Proposition 3.3 (Small Delay and Welfare)}

Under the assumptions of Lemma 3.1, suppose that $\lambda>\underline{\lambda}$, where $\underline{\lambda} \equiv \rho /(\rho+\varepsilon-r)>0$. Then there exists a threshold $\bar{\mu}>0$ such that $d W / d \tau>0$ at $\tau=0$ if and only if $\mu>\bar{\mu}$. That is, small no-commitment delays improve welfare if and only if the economy is initially growing fast enough.

Proof: see appendix A.4.

An intuitive interpretation of the result in Proposition 3.3 is as follows: the larger the initial growth rate $\mu$, the larger initial consumption $C_{0}$ (more on this in section B.1 about leapfrogging). This means that large $\mu$ 's reinforce the level effect. If strong enough, the positive level effect dominates the negative growth effect of a lower $g$, when $\tau>0$, and it leads to higher welfare relative to the no-delay case.

\section{Numerical Examples with CRRA Utility}

\subsection{Investment Commitment}

Our purpose now is to evaluate whether welfare gains are small or large, under investment commitment, when $\lambda$ takes on values that fall within the range documented by Djankov et al. [21], who estimate that values for the credit multiplier range from $35 \%$ in middle-income countries to $85 \%$ in OECD countries. So as to evaluate the robustness of the results reported in Proposition 3.2 , we consider values for $\sigma$ that are larger than one as well as two sets of parameter values which differ only in the values assigned to the world interest rate and to the rate of time preference, as follows.

Assumption 4.1 The two benchmark sets of parameter values are:

(i) $\rho=r=0.01, \varepsilon=0.03$ and $\sigma=2$

(ii) $\rho=r=0.015, \varepsilon=0.03$ and $\sigma=2$

The parameter values in case $(i)$ of Assumption 4.1 accord with case $(i)$ in Proposition 3.2. They imply that the growth rate under autarky (when $\lambda=0$ ) is $g_{a}=(\varepsilon-\rho) / \sigma=1 \%$. Under financial integration, the growth rate ranges from $g=1.5 \%$ when $\lambda=0.35$ to $6.7 \%$ when $\lambda=0.85$, with a value of $2.5 \%$ for the middle value $\lambda=0.6$. The corresponding growth rate increase of 1.5 percentage point under financial globalization belongs to the upper range of estimates (e.g., Henry [26]; see Kose et al. [32] for an extensive survey). Straightforward computations deliver that the compensating variation in consumption is given, when $\sigma \neq 1$, by:

$$
\psi \equiv \frac{C_{0}}{C_{0}^{a}}\left\{\frac{\rho+g_{a}(\sigma-1)}{\rho+g(\sigma-1)}\right\}^{\frac{1}{1-\sigma}}-1 .
$$


Table 1 reports the welfare impact of financial integration under the two scenarios presented in Assumption 4.1.

\begin{tabular}{|c|c|c|c|c|}
\hline \hline Welfare gains in case $(i):$ & $\lambda=0.20$ & $\lambda=0.35$ & $\lambda=0.60$ & $\lambda=0.85$ \\
\hline \hline total $(\psi)=$ & $1.3 \%$ & $4.7 \%$ & $22.5 \%$ & $120.4 \%$ \\
\hline \hline growth effect $=$ & $12.5 \%$ & $26.9 \%$ & $75.0 \%$ & $283.3 \%$ \\
\hline level effect $=$ & $-11.2 \%$ & $-22.2 \%$ & $-52.5 \%$ & $-162.9 \%$ \\
\hline \hline
\end{tabular}

\begin{tabular}{|c|c|c|c|c|}
\hline \hline Welfare gains in case $(\mathrm{ii}):$ & $\lambda=0.20$ & $\lambda=0.35$ & $\lambda=0.60$ & $\lambda=0.85$ \\
\hline \hline total $(\psi)=$ & $-6.1 \%$ & $-9.6 \%$ & $-10.0 \%$ & $25.2 \%$ \\
\hline \hline growth effect $=$ & $8.3 \%$ & $17.9 \%$ & $50.0 \%$ & $188.9 \%$ \\
\hline level effect $=$ & $-14.4 \%$ & $-27.5 \%$ & $-60.0 \%$ & $-163.7 \%$ \\
\hline \hline
\end{tabular}

Table 1: welfare gains from international financial integration relative to autarky with investment commitment, under Assumption 4.1

The top and bottom panels of Table 1 illustrate two possible views of how international financial integration affects welfare. In case $(i)$ corresponding to the top panel, the total welfare gains reported in the second row of the top panel of table 1 are non-trivial even for low $\lambda$ 's that typically reflect the developing stage of middle-income countries. In particular, these figures imply that relaxing the borrowing constraint from a tight $\lambda=20 \%$ to a more generous $35 \%$ imply substantial welfare gains of about $3.4 \%$ of permanent consumption. This suggests that middle-income countries can reap benefits from international financial integration even under tight borrowing constraints. It is important to stress that such welfare gains materialize despite a fall in initial consumption, as depicted in figure 1 , because the autarkic growth rate is no smaller than the world interest rate.

The total gains are then decomposed into the welfare impact of both the growth effect (which is positive) and the level effect (which is negative), in the third and last rows of each panel respectively. That is, $\psi$ is obtained by direct summation of the growth and the level effects. In the top panel of Table 1, the growth-enhancing effect of financial integration is very large even for low $\lambda$ 's, with levels similar to those computed by Obstfeld [35] under global risk-sharing. However, the growth effect is dampened by a substantial negative level effect so that the net effect on welfare is much smaller for developing countries. Table 1 therefore suggests that the level effect is a key dimension to account for if one is to measure welfare changes from international financial integration in a model-consistent way. In fact, while the net effect is sizeable, both gross effects turn out to be very large.

The top panel of Table 1 also shows that welfare gains from international financial integration obtained in our framework require moderate capital inflows. For instance, an increase in welfare of about $2 \%$ occurs when the economy is lent only about $25 \%$ of its capital stock. In addition, it is perhaps useful to compare with the welfare gains brought about by the positive growth effect only, 
e.g. by total factor productivity improvement (that is, an increase in $A$ ). The third row of Table 1 shows that such welfare gains would be much larger, absent the negative level effect.

In the bottom panel of Table 1 corresponding to case (ii) in Assumption 4.1, however, the autarkic growth rate is lower than the world interest rate (that is, $g_{a}=0.75 \%<r=1.5 \%$ ), so that large (potential) welfare losses occur when $\lambda<\lambda_{c}=0.75$. In particular, a welfare loss of about $11 \%$ occurs when $\lambda=\underline{\lambda}=0.5$.It is only when access to international credit markets allows for $\lambda>\lambda_{c}$ that welfare gains follow from borrowing abroad. In case (ii), $g$ equals to $0.9 \%$ when $\lambda=0.35$, to $1.9 \%$ when $\lambda=0.6$ and to $5.0 \%$ when $\lambda=0.85$. The positive growth effect, while significant at low levels of $\lambda$, dominates the negative level effect only when $\lambda>0.75$. Because the autarkic economy growth rate is so small, it is hard to believe that opening up to international credit markets would trigger such large capital inflows, which are nevertheless needed to guarantee that welfare improves.

\subsection{No-Investment-Commitment Delay}

We suspect that the results in section 3.2 extend to $\sigma \neq 1$ but the analysis then becomes much more tedious. We now focus on the empirically appealing case $\sigma>1$ and provide numerical examples when $\tau>0$ that indeed accord with our conjecture. One important corollary of our numerical analysis is that it allows us, in the next sections, to measure the welfare effect of international financial integration, leapfrogging and growth reversals without investment commitment. To do so, we focus on the following benchmark parameter values. ${ }^{13}$

Assumption 4.2 In addition to the parameter values set in case (i) of Assumption 4.1, $\lambda=0.5$ and the initial function is exponential, that is, $K_{I}(t)=e^{\mu t}$ for all $t \in[-\tau, 0]$, with $\mu$ real.

It follows from Assumption 4.2 that when $\tau=0$ (no-delay case), one has that $g=2 \%$ whereas under autarky (when $\lambda=0$ ) the growth rate is $g_{a}=(\varepsilon-\rho) / \sigma=1 \%$. It is also easily shown that when $\tau>0$, the growth rate is such that $2 \%>g>g_{a}$. To simplify matters, let us assume that the initial growth rate is $\mu=3 g$. Our benchmark case is therefore such that the economy is initially growing three times faster than the long-run BGP growth rate. In view of Lemma 3.1, we expect that increasing the no-commitment delay $\tau$ from zero leads to a smaller $g$ but a larger $C_{0}$. The following table and figures show the impact of positive delays on the growth rate loss, the initial consumption level benefit and the overall welfare gain (again measured using the compensating variation in consumption expressed in (8)), relative to the case without delay.

\footnotetext{
${ }^{13}$ The value of $\lambda$ we use again falls within the range of estimates provided by Djankov et al. [21].
} 
Figure 3: plot of growth rate $g$ varying $\tau$

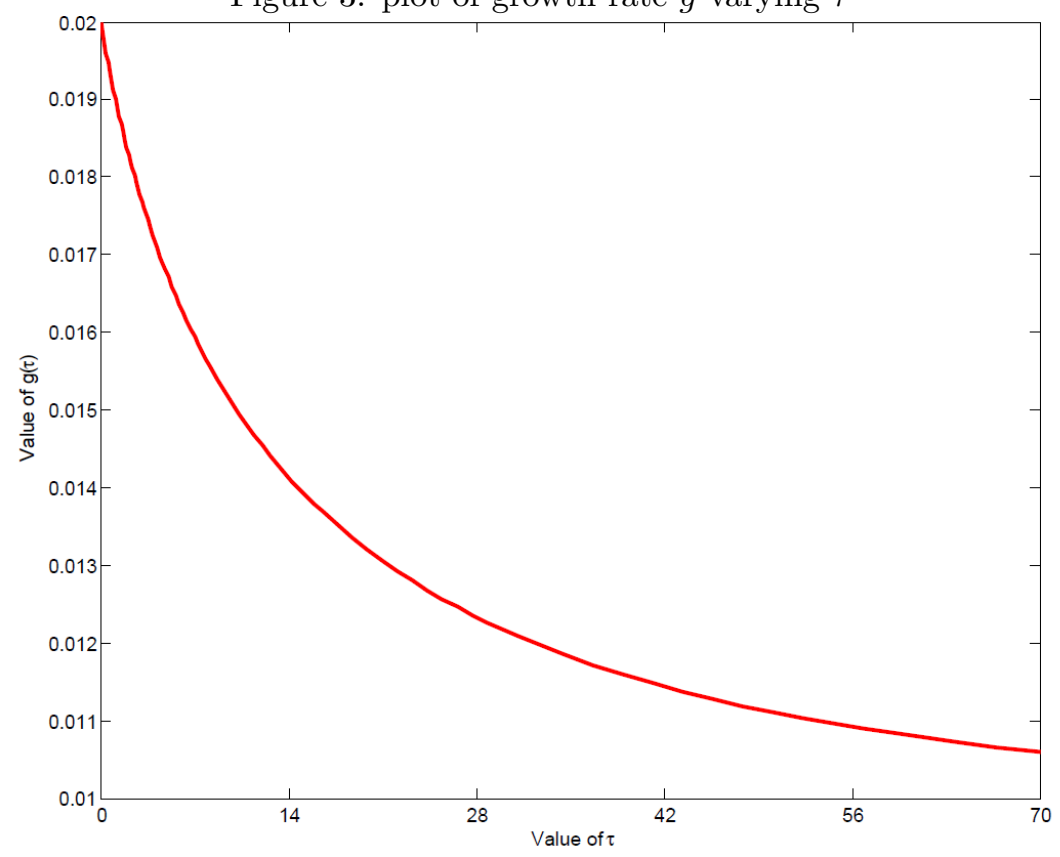

\begin{tabular}{|c|c|c|c|c|c|}
\hline \hline Effect of delay $\tau$ on: & $\tau=0.1$ & $\tau=1$ & $\tau=10$ & $\tau=30$ & $\tau=70$ \\
\hline \hline growth rate loss $=$ & $0.01 \mathrm{pp}$ & $0.09 \mathrm{pp}$ & $0.5 \mathrm{pp}$ & $0.78 \mathrm{pp}$ & $0.94 \mathrm{pp}$ \\
\hline initial consumption gain $=$ & $0.7 \%$ & $6 \%$ & $30 \%$ & $42 \%$ & $41 \%$ \\
\hline total welfare gain $(\psi)=$ & $0.3 \%$ & $2.7 \%$ & $\mathbf{8 . 6} \%$ & $4.8 \%$ & $-3.1 \%$ \\
\hline
\end{tabular}

Table 2 : Effect of no-commitment delay on growth rate loss, initial consumption gain and welfare gain, relative to no-delay case $(\tau=0)$

Figures 3, 4 and 5 plot the levels of growth rate, initial consumption and welfare behind the computations in table 2. For small delays, initial consumption goes up whereas the growth rate goes down exponentially fast when the delay increases, and the overall effect is to improve welfare. Eventually though, the level effect weakens and welfare goes down for large delays, because the negative growth effect then dominates.

The same picture turns out to emerge for different parameter values. Not surprisingly, increasing relative risk aversion $\sigma$ from 2 weakens the incentives to accumulate capital (because the household is now less willing to substitute consumption over time) so that the level effect is stronger and leads to larger welfare gains for small delays. The same effect is at work: when the consumption smoothing motive becomes stronger, slower consumption growth and larger initial consumption follow. 
Figure 4: plot of initial consumption $C_{0}$ varying $\tau$

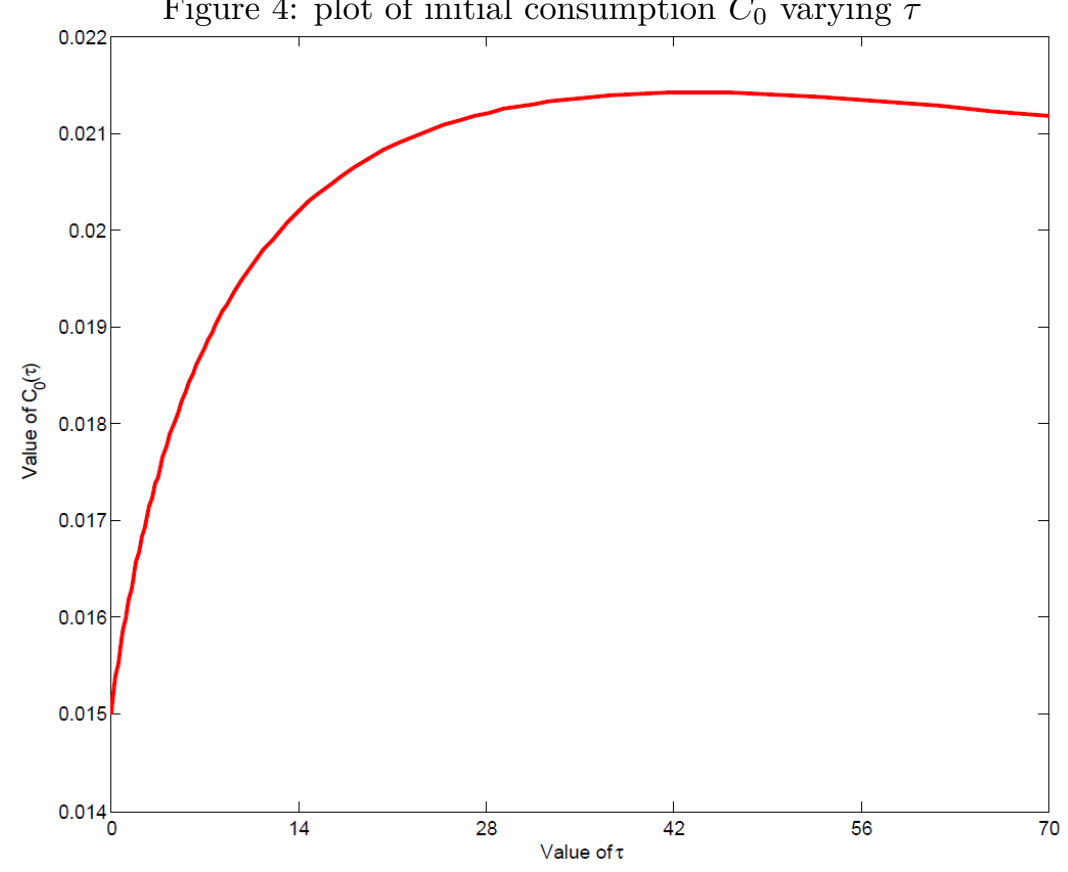

Figure 5: plot of welfare $W$ varying $\tau$

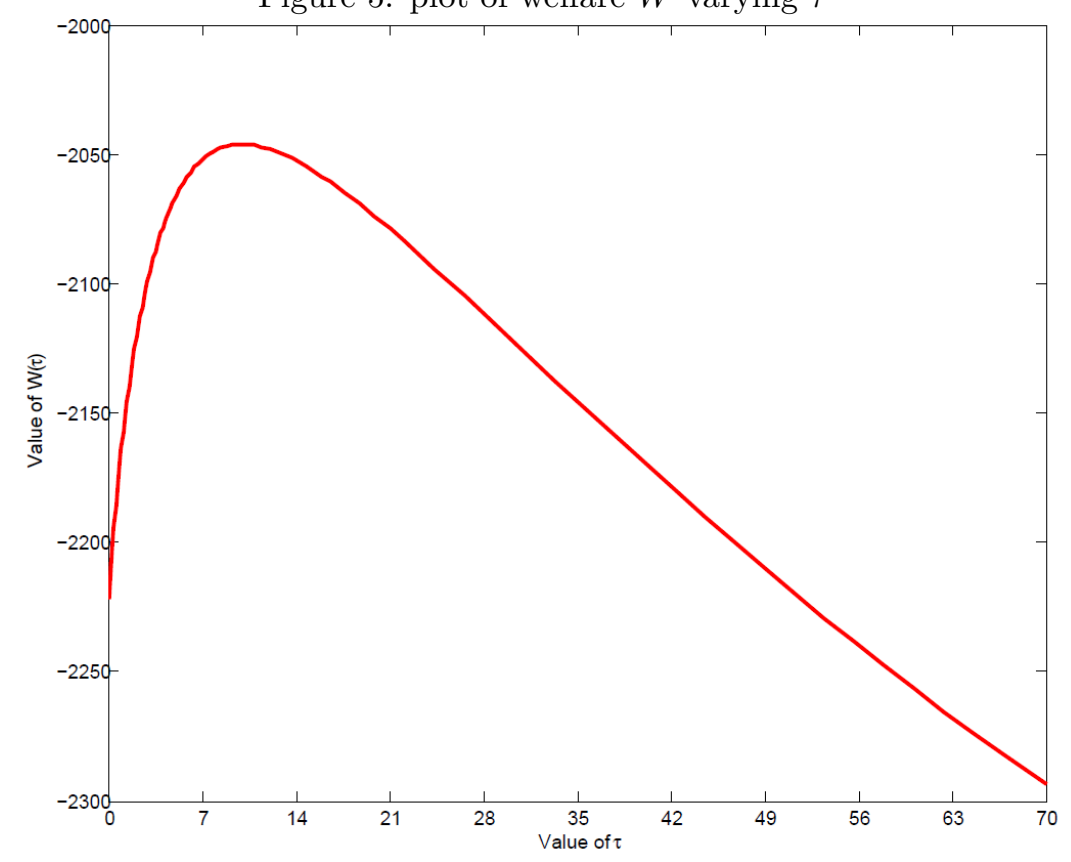


Interestingly enough, the fourth column of table 2 and figure 5 show that there exists a welfaremaximizing delay $\left(\tau_{o p t} \approx 10\right) .{ }^{14}$ Compared to the no-delay case, the optimal $\tau_{\text {opt }}$ delivers a BGP growth rate that goes down from $2 \%$ to $1.5 \%$ (from figure 3, hence a loss of $0.5 \mathrm{pp}$ in table 2) and an initial consumption level that goes up by $30 \%$ (see figure 3). Due to the large positive effect of a much higher consumption level, which dominates the negative growth effect, the combined effect is a non-trivial welfare increase of about $9 \%$ (see table 2 ) relative to the no-delay case $\tau=0$.

In contrast, the last column of table 2 show that for $\tau=70$, the growth rate drops to $1.06 \%$ and the initial consumption gain goes up to $41 \%$ so that welfare declines (see figures $3-5$ ). Because the large growth loss now dominates the consumption gain, households suffer a welfare loss of $-3.1 \%$ compared to the no-delay case. This welfare loss increases to $11.7 \%$ relative to the welfare maximum under $\tau_{\text {opt }}=10$. Therefore, for $\tau$ 's that are much larger than $\tau_{\text {opt }}$, the BGP growth rate is low (and indeed close to that prevailing under autarky) and welfare is significantly lower than the no-delay level. For large delays, the associated loss in the growth rate dominates the consumption gain and leads to large welfare losses. We now apply our analysis to investigate the welfare consequences of financial integration and, in the next section, of leapfrogging and growth reversals.

We now show, again using the compensating consumption criterion (8), that large welfare gains still occur when $\tau>0$. We start by considering an economy with parameters given by case (i) of Assumption 4.1 that imply $g_{a}=1 \%$ under autarky. The previous section has shown that a positive no-commitment delay hampers growth. Therefore, we make the conservative assumption that the level of credit market imperfections is non-trivial by setting the no-commitment delay to $\tau=10$, so that the growth rate under financial integration is at most $g=2 \%$ when $\lambda=0.85$ (compared to about $6.7 \%$ in the no-delay case). Therefore, the maximal increment in the growth rate is 1 percentage point. In addition, we assume that the economy was under autarky for $t \in[-\tau, 0]$, therefore growing slowly at $\mu=g_{a}=1 \%$, and that it switches at $t=0$ from autarky to financial integration with a positive $\lambda$. Table 3 reports that large welfare gains still obtain despite the welfare-reducing impact of relaxing the assumption of investment commitment.

\begin{tabular}{|c|c|c|c|c|}
\hline \hline Welfare gains: & $\lambda=0.20$ & $\lambda=0.35$ & $\lambda=0.60$ & $\lambda=0.85$ \\
\hline \hline total $(\psi)=$ & $0.6 \%$ & $2.0 \%$ & $6.3 \%$ & $13.3 \%$ \\
\hline \hline growth effect $=$ & $8.4 \%$ & $16.1 \%$ & $32.1 \%$ & $52.2 \%$ \\
\hline level effect $=$ & $-7.8 \%$ & $-14.1 \%$ & $-25.8 \%$ & $-38.9 \%$ \\
\hline \hline
\end{tabular}

Table 3: welfare gains from international financial integration relative to autarky without investment commitment

Not surprisingly, the welfare gains reported in the second row of table 3 are reduced under the more realistic scenario that investment commitment is not possible, in a very nonlinear fashion. In particular, compared to the no-delay case in the top panel of table 1, welfare gains are drastically

\footnotetext{
${ }^{14}$ Robustness analysis shows that this property holds for an open set of parameter values. In particular, $\tau_{o p t}$ is larger for larger $\sigma$ 's and $\mu$ 's. For example, other things equal, $\tau_{\text {opt }}=86$ when $\sigma=5$ and $\tau_{\text {opt }}=2$ when $\mu=1.5 \mathrm{~g}$.
} 
reduced when $\lambda \geq 0.6$, that is, for developed economies. However, they remain significant when compared, for instance, to the welfare gains from removing business cycle (Barlevy [6]). The third and last rows of table 3 show that both the growth effect (which is again commensurate to the figures computed in Obstfeld [35] for reasonable $\lambda$ 's) and the level effect are large. Table 3 also reveals that welfare gains of about $2 \%$ appear if the economy is lent about a third of its capital stock.

In view of the fact that few economies are closed to capital inflows, it is also interesting to compare the welfare gains generated by increasing financial openness. That is, consider an economy contemplating borrowing more from international credit markets. Table 4 reports how much more consumption is enjoyed by an economy moving from $\lambda=0.2$ (and correspondingly $\mu \approx 1.2 \%>g_{a}$ ) to larger $\lambda$ 's.

\begin{tabular}{|c|c|c|c|}
\hline \hline Welfare gains: & $\lambda=0.35$ & $\lambda=0.60$ & $\lambda=0.85$ \\
\hline \hline$\psi=$ & $1.65 \%$ & $6.6 \%$ & $14.7 \%$ \\
\hline \hline
\end{tabular}

Table 4: welfare gains from deeper international financial integration relative to $\lambda=0.2$ without investment commitment

Here again, substantial welfare gains follow from larger financial integration at the international level. The real-world scenario that table 4 illustrates is such that international financial markets become more generous in the sense that the economy is able to borrow more. However, it is also relevant to interpret $\lambda$ as a policy lever, in the sense that economic policymakers may be willing to impose capital control. In particular, discussions in policy circles every now and then consider adopting debt-reducing policies that aim at boosting investment and output by reducing debt payments. Our analysis enables us to quantify the welfare effects of such policies. We now ask by how much welfare is reduced if the government of a financially integrated country would choose to reduce $\lambda$ from 0.85 , which corresponds to a debt-to-GDP ratio of about $69 \%$, all the way down to $\lambda=0.2$ which yields a debt-to-GDP ratio of about $18 \%$. The outcome appears in table 5 .

\begin{tabular}{|c|c|c|c|}
\hline \hline Welfare gains: & $\lambda=0.6$ & $\lambda=0.35$ & $\lambda=0.2$ \\
\hline \hline$\psi=$ & $-1.3 \%$ & $-8.7 \%$ & $-11.5 \%$ \\
\hline \hline
\end{tabular}

Table 5: welfare losses from debt-reducing policies relative to $\lambda=0.85$ without investment commitment

The welfare losses reported in table 5 are mirror images of the welfare gains of deeper financial integration. Even though such losses are large, a surprising corollary follows. The policies described by table 5 may be illustrated by figure 1 again, where the consumption now tilts clockwise when $\lambda$ is reduced. In other words, reducing the debt-to-GDP ratio increases initial consumption $C_{0}$ at the expense of reducing the growth rate $g$. This means that seeking a majority supporting such policy proposals may not be such a daunting task as it may seem at first sight, in the sense that the immediate impact is to increase consumption so that short-run gains are traded for long-run 
pains.

In Appendix B, we derive additional results about the welfare consequences of leapfrogging and growth breaks.

\section{Conclusion}

In this paper, we have derived conditions under which collateral-constrained access to international borrowing triggers large welfare gains under endogenous growth and entry cost to access international credit markets. These conditions turn out to be simple enough and connected to the distance between the growth rate and the world interest rate. Despite a loss in initial consumption when the economy switches from autarky to financial integration, the growth-enhancing effect of financial globalization generates substantial welfare gains. Such benefits are robust to relaxing the assumption of investment commitment, which is shown both to hamper long-run growth and to originate growth volatility. Under this more conservative hypothesis, significant welfare benefits still follow from international financial integration under imperfect credit markets. However, our analysis also stresses that such welfare gains are restricted to economies that were growing faster than the interest rate prior to becoming financially integrated. This condicio sine qua non contrasts with the usual textbook view, which predicts unconditional welfare benefits from international financial integration. In our framework, welfare gains occur only if the borrowing country has put in place, while autarkic, institutions that lead to high growth (e.g. top quality governance or efficient domestic financial markets). In that sense, our results do not disagree with the view that foreign borrowing improves welfare only if growth is strong enough.

We are of course not the first to emphasize that large welfare gains obtain under endogenous growth. Most notably, the literature on risk-sharing typically emphasizes the growth-enhancing effect of financial globalization (Obstfeld [35], Acemoglu and Zilibotti [1], van Wincoop [40] and many others). In contrast, we focus on a deterministic model where this channel is absent and, therefore, does not contribute to welfare improvement. As a consequence, one important limitation of our analysis is that consumption volatility is entirely eliminated in our models, in which consumption growth is smooth under financial integration. In that respect, we show that endogenous debt constraints do not prevent consumption smoothing in a setting with endogenous growth. It remains to be studied whether or not welfare gains remain non-trivial in a stochastic extension of the model. Introducing risk-sharing would obviously lead to even larger welfare gains. However, as documented by, e.g., Kose et al. [31], financial globalization may also increase consumption volatility and this points at potential welfare-reducing channels. Along these lines, a particularly relevant extension would be to acknowledge that, in the real world, capital inflows are volatile and a source

of shocks to the domestic economy, building for instance upon the analysis of Mendoza [33]. Solving the stochastic optimal control problem under a law of motion governed by an NDE is a challenging task that has to be addressed along the way. Our results derived in a benchmark deterministic 
economy still suggest that potential welfare-reducing channels have to be strong enough if they are to reverse our conclusion that welfare gains from international financial integration, though conditional, may be large.

The literature lacks studies that evaluate and compare the welfare gains arising from both trade and financial integration. Brooks and Dovis [14] provide some theory and firm-level evidence that forward-looking credit constraints lead to larger gains from trade liberalization than backwardlooking borrowing constraints of the type we use in this paper. It remains to be seen whether such forward-looking constraints, that depend on the discounted profit flows derived from the firms' operations, also lead to larger welfare gains from financial globalization, which seems likely given the expected reallocation of firms. This line of reasoning suggests that the level of welfare gains obtained in our paper could well be a lower bound. On a different topic, developing a framework with overlapping generations would help evaluate, in a more quantitative manner, how much pain early generations are expected to suffer from financial liberalization. Such an extension would be very useful to assess the conditions such that a voting majority would resist large-scale integration, which could shed some light on the reasons why certain countries hesitate to embrace trade and financial globalization. In addition it would also be interesting to develop a two-country version of the model.

Finally, our analysis also emphasizes that, under endogenous growth, financial globalization triggers a large level effect that conflicts with the growth effect. However, only the latter has been tracked and documented in empirical studies (e.g. Henry [26], Kose et al. [32]). Casual evidence suggests that large capital inflows are likely to have played an active part in the spending sprees that have preceded implicit or explicit default episodes, for example in Southern American or Southern European countries over the last twenty years. Of course, such historical records are not well explained by our model because, if anything, those countries did not face in the past tight credit constraints of the sort emphasized in our and other papers. In view of recent events, though, it could well be that efforts aimed at preventing default will lead, in the future, to more effective borrowing limits that resemble those formalized in our paper. In any event, our results stress that any empirical metric of welfare changes under financial globalization should take into account, so as to map growth benefits or losses into welfare, how consumption evolves following a switch from autarky to financial integration, or following deeper financial integration. We believe this also calls for future research.

\section{References}

[1] Acemoglu, D., Zilibotti, F. (1997). Was Prometheus unbound by chance? Risk, diversification and growth. Journal of Political Economy 105: 709-751. 5, 23

[2] Aghion, P., Bacchetta, P., Banerjee, A. (2004). Financial development and the instability of open economies. Journal of Monetary Economics 51: 1077-1106. 3 
[3] Antràs, P., Caballero, R. (2009). Trade and capital flows: a financial frictions perspective. Journal of Political Economy 117: 701-744. 2

[4] Antràs, P., Caballero, R. (2011). On the role of financial frictions and the saving rate during trade liberalizations. Journal of the European Economic Association 8: 442-455. 2, 5

[5] Aoki, K., Benigno, G., Kiyotaki, N. (2010). Adjusting to capital account liberalization. CEPR Discussion Papers 8087. 2

[6] Barlevy, G. (2004). The cost of business cycles under endogenous growth. American Economic Review 94: 964-990. 3, 10, 22

[7] Barro, R., Mankiw, N.G., Sala-i-Martin, X. (1995). Capital mobility in neoclassical models of growth. American Economic Review 85: 103-15. 3, 5

[8] Bellman, R., Cooke, K. (1963). Differential-difference equations. Academic Press: New-York. 8

[9] Bensoussan, A., Da Prato, G., Delfour, M.C., Mitter, S.K. (2007). Representation and control of infinite dimensional system. Second edition. Birkhäuser: Boston. 8, 29

[10] Boucekkine, R., Fabbri, G., Pintus, P. (2012). On the optimal control of a neutral delay differential equation arising in economics. Optimal Control Applications and Methods 33: 501-530. 8, 28,29

[11] Boucekkine, R., Pintus, P. (2012). History's a curse: leapfrogging, growth breaks and growth reversals under international borrowing without commitment. Journal of Economic Growth 17: 27-47. 4, 6, 8, $14,31,32,33$

[12] Bretschger, L., Steger, T. (2004). The dynamics of economic integration: theory and policy. International Economics and Economic Policy 1: 119-134. 5

[13] Broner, F., Ventura, J. (2010). Rethinking the effects of financial liberalization. Mimeo CREI and Universitat Pompeu Fabra. 2

[14] Brooks, W., Dovis, A. (2013). Credit market frictions and trade liberalization. Mimeo University of Notre Dame and Pennsylvania State University. 24

[15] Burns, J.A., Herdman, T.L., Stech H.W. (1983). Linear functional differential equations as semigroups on product spaces. SIAM Journal on Mathematical Analysis 14: 98-116. 28

[16] Bussière, M., Fratzscher, M. (2008). Financial openness and growth: short-run gain, long-run pain? Review of International Economics 16: 69Ü95. 4

[17] Carlstrom, C., Fuerst, T., Paustian, M. (2016). Optimal contracts, aggregate risk and the financial accelerator. American Economic Journal: Macroeconomics 8: 119-147. 7

[18] Cohen, D., Sachs, J. (1986). Growth and external debt under risk of debt repudiation. European Economic Review 30: 526-560. 3, 7, 8 
[19] Cuberes, D., Jerzmanowski, M. (2009). Democracy, diversification and growth reversals. Economic Journal 119: 1270-1302. 4

[20] Devereux, M., Yetman, J. (2010), Leverage constraints and the international transmission of shocks. Journal of Money Credit and Banking 42: 71-105. 3

[21] Djankov, S., Hart, O., McLiesh, C., Shleifer, A. (2008). Debt enforcement around the world. Journal of Political Economy 116: 1105-1149. 16, 18

[22] Eaton, J., Gersovitz, M. (1981). Debt with potential repudiation: theoretical and empirical analysis. Review of Economic Studies 48: 289-309. 3

[23] Epaulard, A., Pommeret, A. (2005). Financial integration, growth, and volatility. IMF Working Papers 05/67, International Monetary Fund. 5

[24] Gosh, P., Ray, D. (1996). Cooperation in community interaction without information flows. Review of Economic Studies 63: 491-519. 4

[25] Hausmann, R., Pritchett, L., Rodrik, D. (2005). Growth accelerations. Journal of Economic Growth 10: $303-329.4$

[26] Henry, P.B. (2003). Capital account liberalization, the cost of capital, and economic growth. American Economic Review 93: 91-96. 16, 24

[27] Hoxha, I., Kalemli-Ozcan, S., Vollrath, D. (2013). How big are the gains from international financial integration? Journal of Development Economics. 103: 90-98. 5

[28] Jones, B., Olken, B. (2008). The anatomy of start-stop growth. Review of Economics and Statistics 90: 582-587. 4

[29] Kaminsky, G., Schmukler, S. (2008). Short-run pain, long-run gain: financial liberalization and stock market cycles. Review of Finance 12: 253-292. 3

[30] Kappel F., Zhang K.P. (1986). Equivalence of functional-differential equations of neutral type and abstract Cauchy problems. Monatshefte fur Mathematik 101: 115-133. 28, 29

[31] Kose, A., Prasad, E., Rogoff, K., Wei, S.-J. (2007). Financial globalization, growth and volatility in developing countries. In Harrison, A., Ed., Globalization and poverty. University of Chicago Press. 23

[32] Kose, A., Prasad, E., Rogoff, K., Wei, S.-J. (2009). Financial globalization: a reappraisal. IMF Staff Papers 56: 8-62. 6, 16, 24

[33] Mendoza, E. (2010). Sudden stops, financial crises and leverage. American Economic Review 100: 1941-1966. 23

[34] Mendoza, E., Quadrini, V., Rios-Rull, J.V. (2009). On the welfare implications of financial globalization without financial development. NBER International Seminar on Macroeconomics 2007, R. Clarida and F. Giavazzi, Eds., 283-312. 2 
[35] Obstfeld, M. (1994). Risk-taking, global diversification and growth. American Economic Review 85: 1310-1329. 5, 17, 22, 23

[36] Obstfeld, M. (2009). International finance and growth in developing countries: what have we learned? IMF Staff Papers 56: 63-111. 6

[37] Rancière, R., Tornell, A., Westermann, F. (2008). Systemic crises and growth. Quarterly Journal of Economics 123: 359-406. 2, 5

[38] Schularick, M., Steger, T. (2010). Financial integration, investment, and economic growth: evidence from two eras of financial globalization. The Review of Economics and Statistics 92: 756-768. 2, 6

[39] Shampine, L.F. (2009). Dissipative approximations to neutral DDEs. Applied Mathematics and Computation 203: 641-648. 33

[40] van Wincoop, E. (1999). How big are potential welfare gains from international risksharing? Journal of International Economics 47: 109-135. 5, 23

\section{A Proofs}

\section{A.1 Proof of Proposition 2.1}

The optimal control problem is as follows:

$$
\max _{C, D, I, K} \int_{0}^{\infty} e^{-\rho t} \frac{C(t)^{1-\sigma}-1}{1-\sigma} d t
$$

subject to the constraints on budget, capital accumulation and debt:

$$
\begin{aligned}
\dot{D}(t) & =I(t)+r D(t)+C(t)-A K(t) \\
\dot{K}(t) & =I(t)-\delta K(t) \\
\lambda K(t-\tau) & \geq D(t)
\end{aligned}
$$

given the initial capital stock $K(0)>0$. Denote $\psi, \phi$ and $\mu$ the multipliers associated to (10), (11) and (12), respectively. The regime where constraint (12) is slack is such that $\mu=0$ by the complementary slackness condition. Therefore, a permanent regime with interior solutions and a slack debt constraint is characterized by the following first-order conditions with respect to $C, D$, I, $K$ :

$$
\begin{aligned}
C^{-\sigma}(t) & =-\psi(t) \\
-r \psi(t) & =\dot{\psi}(t)-\rho \psi(t) \\
\psi(t)+\phi(t) & =0 \\
A \psi(t)+\delta \phi(t) & =\dot{\phi}(t)-\rho \phi(t)
\end{aligned}
$$


Using (14) to solve for $\psi$, one gets that $\psi(t)=\psi(0) e^{(\rho-r) t}$. Moreover, using that $\psi=-\phi$ from (15) and then solving (16) for $\phi$, one gets that $\phi(t)=\phi(0) e^{(\delta+\rho-A) t}$. It follows that the necessary condition $\psi(t)=-\phi(t)$ for all $t \geq 0$ is satisfied only if $A-\delta=r$ so that a permanent regime with slack constraint (12) does not exist if $A-\delta \neq r$.

It follows from the above analysis that an unbounded solution with infinite investment $I$ is optimal when $A-\delta>r$. To show this, one can plug $\psi(t)=\psi(0) e^{(\rho-r) t}$ into (16) and solve it for $\phi$, which gives:

$$
\phi(t)=c e^{(\rho+\delta) t}-\frac{A}{r+\delta} \psi(t),
$$

where the constant $c$ is given by $c \equiv \phi(0)+A \psi(0) /(r+\delta)$. It follows from (17) that $\psi(t)+\phi(t)>0$ for all $t>0$ if and only if $c e^{(r+\delta) t}>-\psi(0)[1-A /(r+\delta)]$. For the latter inequality to hold, it suffices that $c>-\psi(0)[1-A /(r+\delta)]$, which is easily shown to be met when $A-\delta>r$, provided that $\psi(0)+\phi(0)>0$. It follows that the debt constraint (12) binds for all $t \geq 0$. QED

\section{A.2 Sketch of Proof of Proposition 2.2}

As already recalled in Section 2 the problem of maximizing (1) subject to (3) is non-standard for the presence of delayed terms in the state equation. Indeed (3) is a neutral differential equation (NDE), a generalized form of delay differential equation (DDE) where, beside the presence of the unknown in delayed form, the retarded derivative of the unknown shows up. Systems driven by DDEs are infinite dimensioned, so, a fortiori, working with NDEs implies working in an infinite dimensional framework.

In [10] we deal with the optimal control problem (1)-(3) both using the maximum principle and the dynamic programming, we recall here how the latter, that allowed us to find a finer characterization of the solution, works. It is indeed possible to rewrite the state equation (3) as an equivalent evolution equation in a suitably chosen Hilbert space. In the reformulated state equation the delays (of the unknown and its derivative) do not explicitly appear but the intrinsic infinite dimensional nature of the system stays on. We adapt for this aim the approach introduced by Burns [15] and Kappel and Zhang [30] where the chosen Hilbert space is given by $M^{2}:=\mathbf{R} \times L^{2}(-T, 0)$ : every element $x$ of $M^{2}$ is given by a couple $\left(x_{0}, x_{1}\right)$ composed by a real number $x_{0}$ and a square integrable function $x_{1}:[-\tau, 0] \rightarrow \mathbf{R}$. It turns out (see [10] for details) that the solution of (3) is related to the solution of the following equation:

$$
\left\{\begin{array}{l}
\dot{x}(t)=G x(t)-(1,0) C(t) \\
x(0)=\left(x_{0}, x_{1}\right)
\end{array}\right.
$$

where $G$ is the operator defined as

$$
\left\{\begin{array}{l}
D(G):=\left\{\left(x_{0}, x_{1}\right) \in M^{2}: x_{1} \in W^{1,2}(-\tau, 0), x_{0}=x_{1}(0)-\lambda x_{1}(-\tau)\right\} \\
G\left(x_{0}, x_{1}\right):=\left((A-\delta) x_{1}(0)-r \lambda x_{1}(-\tau), \partial x_{1}\right)
\end{array}\right.
$$


(being $\partial x_{1}$ the derivative of the function $x_{1}$ and $W^{1,2}$ the Sobolev space of indexes $(1,2)$ ). More precisely, given $K(\cdot)$ the unique (generalized in the sense of [30]) solution of (3), if we denote, for $t \geq 0$

$$
\left\{\begin{array}{l}
K_{t}:[-\tau, 0] \rightarrow \mathbf{R} \\
K_{t}(s):=K(t+s)
\end{array}\right.
$$

and by $x(\cdot)$ the unique (mild in the sense defined e.g. by Bensoussan et. al [9] in Section II-1.3) solution of (18) we have that, for $t \geq 0$,

$$
x(t)=\left(x_{0}(t), x_{1}(t)\right)=\left(K(t)-\lambda K(t-\tau), K_{t}\right) .
$$

This fact allows to "translate" the initial optimal control problem (1)-(3) into an equivalent optimization problem in the $M^{2}$ environment: maximizing (1) subject to (18).

The Hamilton-Jacobi-Bellman (HJB) equation related to the new problem is

$$
\rho v(x)=\left\langle x, G^{*} D v\right\rangle_{M^{2}}+\sup _{C \geq 0}\left(-C\langle(1,0), D v(x)\rangle_{M^{2}}+\frac{C^{1-\sigma}}{1-\sigma}\right) .
$$

It is a partial differential equation in the Hilbert space $M^{2}\left(G^{*}\right.$ denotes the adjoint of the operator $G$ characterized in Proposition 5.3 of [10]).

An explicit solution of (22), on a proper open subset $E$ of $M^{2}$ containing the states that are interesting from the economic problem, can be explicitly found (see Theorem 5.5 of [10]) and it is given by

$$
v\left(x_{0}, x_{1}\right)=\alpha\left(x_{0}+\beta \int_{-\tau}^{0} e^{-\xi s} x_{1}(s) d s\right)^{1-\sigma}
$$

where $\xi$ is the constant described in Proposition 2.2, $\alpha=\frac{1}{1-\sigma}\left(\frac{\rho-(1-\sigma) \xi}{\sigma}\right)^{-\sigma}$ and $\beta=-\frac{\lambda(A-\delta-r)}{\lambda-e^{\xi \tau}}$.

Using a verification argument (see Proposition 5.6 of [10]) we can prove that $v$ is indeed the value function of the problem in $M^{2}$ (i.e. the maximal attainable welfare). "Translating" the expression of $v$ in terms of the variable $K$ (and reintroducing then the delays) we obtain

$$
V\left(K_{I}\right)=\alpha\left\{\left(K_{I}(0)-\lambda K_{I}(-\tau)\right)+(\delta+\xi-A) \int_{-\tau}^{0} e^{-\xi s} K_{I}(s) d s\right\}^{1-\sigma} .
$$

This is the expression used to compute the welfare in Section 3.2. Using again a verification argument (see again Proposition 5.6 of [10]) we can also prove that the feedback induced by $v$ is indeed optimal. This means that it gives, at any time, the optimal consumption in terms of the state of the system described by $x$. The feedback is given by

$$
\left\{\begin{array}{l}
\phi: E \rightarrow \mathbf{R} \\
\phi(x):=\arg \max _{C \geq 0}\left(-C\langle(1,0), D v(x)\rangle_{M^{2}}+\frac{C^{1-\sigma}}{1-\sigma}\right) \\
\quad=\langle D v(x),(1,0)\rangle^{-1 / \sigma}=\left(\frac{\rho-(1-\sigma) \xi}{\sigma}\right)\left\langle x,\left(1, s \mapsto \beta e^{-s \xi}\right)\right\rangle .
\end{array}\right.
$$

"Translating" the feedback in terms of the variable $K$, we can prove (Proposition 4.6 of [10]) that the associated optimal consumption path is exponential. Its explicit expression is described in Proposition 2.2. 


\section{A.3 Proofs of Propositions 3.1 and 3.2}

Proof of Proposition 3.1: from Proposition 2.2, we get that, when $\tau=0, g=(\xi-\rho) / \sigma>g_{a}$, where $\xi=(\varepsilon-r \lambda) /(1-\lambda)$ is the unique positive root of the characteristic function $Q(x)=x-\lambda x-\varepsilon+r \lambda$. It follows that $d g / d \lambda>0$ if $\varepsilon>r$ or $A-\delta-r>0$. In addition, the expression of $C_{0}$ in (4) simplifies to:

$$
C_{0}=\left\{\frac{\rho(1-\lambda)}{\sigma}+\frac{\sigma-1}{\sigma}(\varepsilon-r \lambda)\right\} K_{I}(0)
$$

It follows that $d C_{0} / d \lambda<0$ if and only if $1-\sigma<\rho / r$, which is met if $\sigma \geq 1$. QED

Proof of Proposition 3.2: from the expression in (6) that obtains when $\sigma=1$, one gets that:

$$
\frac{d W}{d \lambda}=\frac{1}{\rho}\left\{\frac{d C_{0} / d \lambda}{C_{0}}+\frac{d \xi / d \lambda}{\rho}\right\}
$$

Using the expressions for $\xi$ and $C_{0}$ derived, under the assumption that $\sigma=1$, in the proof of Proposition 3.1, one gets that $d \xi / d \lambda=(\xi-r) /(1-\lambda)$ and $d C_{0} / d \lambda=-\rho$ so that straightforward computations deliver that $d W / d \lambda>0$ if and only if $g>r$ or, equivalently, $g_{a} \equiv A-\delta-\rho>r-\lambda \rho$. It follows that two cases occur:

(i) if $g_{a} \geq r$, then $d W / d \lambda>0$ for all $\lambda \geq 0$.

(ii) if $r>g_{a}>r-\rho$, then $d W / d \lambda>0$ if and only if $\lambda>\underline{\lambda} \equiv\left(r-g_{a}\right) / \rho$. It follows from (7) that $\psi>0$ if and only if $\lambda>\lambda_{c}>\underline{\lambda}$, where $\lambda_{c}$ is the unique positive solution to $C_{0}\left\{e^{\frac{g-g_{a}}{\rho}}\right\}=C_{0}^{a}$, or equivalently $\lambda(\varepsilon-r)=-\rho(1-\lambda) \ln (1-\lambda)$, given that $\psi$ tends to $\infty$ when $\lambda$ tends to one from below. QED

\section{A.4 Proofs of Lemma 3.1 and Proposition 3.3}

Proof of Lemma 3.1: under logarithmic utility, one gets from equation (4) the expression of the optimal initial consumption level and it is then straightforward to show that, evaluated at $\tau=0$, $d C_{0} / d \tau=\rho K_{I}(0)(\lambda \mu+\xi-\varepsilon)>0$, where $\mu \equiv \dot{K}_{I}(0) / K_{I}(0)$, using that $\xi=(\varepsilon-r \lambda) /(1-\lambda)$ when $\tau=0$, and the assumption that $\mu>\underline{\mu}$ where $\underline{\mu} \equiv(r-\varepsilon) /(1-\lambda)<0$. QED

Proof of Proposition 3.3: Using the expressions of both $d C_{0} / d \tau$ in the proof of Lemma 3.1 and $W$ in equation (6), one computes that:

$$
\frac{d W}{d \tau}=\frac{1}{\rho}\left\{\frac{\lambda \mu+\xi-\varepsilon+[\lambda \xi(r-\xi)] / \rho}{1-\lambda}\right\}
$$

at $\tau=0$ so that $d W / d \tau$ and $\phi \equiv \lambda \mu+\xi-\varepsilon+[\lambda \xi(r-\xi)] / \rho$ have the same sign. Using that $\xi=(\varepsilon-r \lambda) /(1-\lambda)$ when $\tau=0$, it is then easy to show that $\xi+[\lambda \xi(r-\xi)] / \rho<0$ if and only if $\lambda>$ $\underline{\lambda} \equiv \rho /(\rho+\varepsilon-r)$. It then follows that there exists a threshold value $\bar{\mu} \equiv-\{\xi-\varepsilon+[\lambda \xi(r-\xi)] / \rho\} / \lambda>0$ such that $\phi>0$ if and only if $\mu>\bar{\mu}$. QED 


\section{B Additional Results on Leapfrogging and Growth Breaks}

\section{B.1 Large Welfare Gains from Leapfrogging}

We define leapfrogging in consumption as the fact that the larger the initial growth rate $\mu$, the more consumption and the larger welfare that is enjoyed by households. Suppose that economy $\mathcal{A}$, say, had a lower initial growth rate $\mu$ and was richer (in terms of capital and output) but growing more slowly prior to $t=0$ than economy $\mathcal{B}$. In view of our assumption that growth is exponential for $t \in[-\tau, 0]$, both countries end up with the same capital stock, which equals unity, at $t=0$. Then leapfrogging means that $\mathcal{B}$ gets to enjoy a larger consumption level $C_{0}$ at $t=0$, hence a larger consumption at all dates $t \geq 0$ (because consumption jumps to the BGP at $t=0$ and the growth rate $g$ does not depend on $\mu$ ). In contrast, $\mathcal{B}$ had lower capital and output than $\mathcal{A}$, for $t \in[-\tau, 0]$.

To study the welfare effect of leapfrogging, we set $\tau=10$ so that $g=1.5 \%$ independent of the initial growth rate $\mu$ over $[-\tau, 0]$. Therefore, any welfare change due to variations in $\mu$ occur because of changes in the initial consumption level. In other words, for a given $\tau$, only the short-run level effect originates welfare changes when $\mu$ is made to vary. In fact, it is not difficult to show that, given $\tau$ not too large, the level effect is positive on welfare, that is, $d C_{0} / d \mu>0$ under CRRA utility. In particular, welfare gains are generated by leapfrogging for $\tau=10$, as illustrated by table 6 .

\begin{tabular}{|c|c|c|c|c|}
\hline \hline Effect of initial growth rate $\mu$ on: & $\mu=-g$ & $\mu=0$ & $\mu=g$ & $\mu=3 g$ \\
\hline \hline initial consumption gain $=$ & $48 \%$ & $66 \%$ & $82 \%$ & $107 \%$ \\
\hline \hline
\end{tabular}

Table 6: Consumption gain of leapfrogging relative to initial growth rate $\mu=-3 g$

Figure 6 plots $C_{0}$ as a function of $\mu$ and $\lambda$. It shows that given $\lambda$, the initial consumption level increases with the initial growth rate. in other words, leapfrogging occurs: the faster growth in the initial time interval, the higher consumption. For the chosen parameter values (see assumption 4.1), there is always leapfrogging for reasonable $\mu$ 's, which turns out to be also true for larger values of $\tau$ 's. ${ }^{15}$ Note that relative risk aversion $\sigma$ has no impact on the relative consumption gains because it affects only the scaling factor of $C_{0}$ (see equation (4)).

Table 6 shows that consumption gains due to leapfrogging can be very large. For example, suppose that economy $\mathcal{A}$ has been declining at $\mu=-3 g=-4.5 \%$, implying (in annualized data) that it takes 16 years to halve consumption. In contrast, economy $\mathcal{B}$ has been enjoying fast growth at $\mu=3 g=4.5 \%$ so that its consumption is expected to double in 16 years. Then $\mathcal{B}$ enjoys an initial consumption that is about twice as large as that of $\mathcal{A}$. Sensitivity analysis shows that leapfrogging still generates large consumption gains for large delays, for reasonable values of $\mu$. It is also worth noting that the larger $\lambda$, the bigger welfare gains due to leapfrogging, as one can see in figure 6 . One also notes from figure 6 that, given $\lambda$ larger than $0.5, C_{0}$ is a concave function of $\mu$, which indicates that the welfare gains from leapfrogging are asymmetric: they are much more important for countries that have initially been either declining or growing very slowly. In other words, an

\footnotetext{
${ }^{15}$ This is in contrast with what happens in the Solow case studied by Boucekkine and Pintus [11].
} 
Figure 6: plot of initial consumption $C_{0}$ varying $\lambda$ and $\mu$

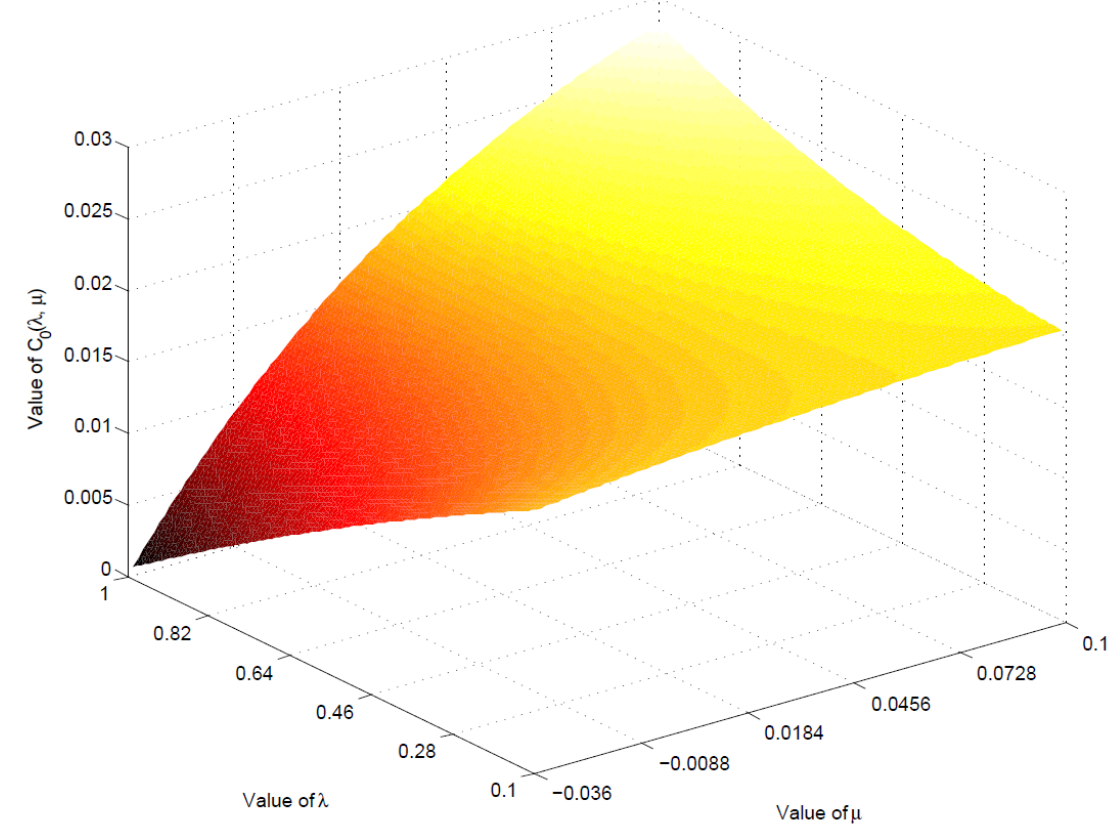

increase of $1 \mathrm{pp}$ in the initial growth rate generates larger welfare gains from leapfrogging when $\mu$ is small or negative.

Finally, a striking feature in figure 6 is that the effect of the credit multiplier $\lambda$ on initial consumption $C_{0}$ is positive when $\mu$ is positive and large enough but reverses for negative $\mu$ 's. This suggests that, for a given delay, financial globalization may decrease welfare if the economy is initially declining.

\section{B.2 Significant Welfare Losses from Growth Reversals}

We now study the implications of our results for welfare when growth reversals occur. As in Boucekkine and Pintus [11], we define a growth reversal as a sudden break in the growth rate, when the latter goes either from below to above trend or from above to below trend. The next proposition shows that the condition for growth reversals is identical to that derived in Boucekkine and Pintus [11] for the Solow case (the proof is similar and therefore omitted). To derive such a condition, it is more convenient to study the detrended NDE arising when we perform the change of variable $x(t)=e^{-g t} K(t)$. 
Figure 7: plot of log of detrended capital against time when $\tau=10$

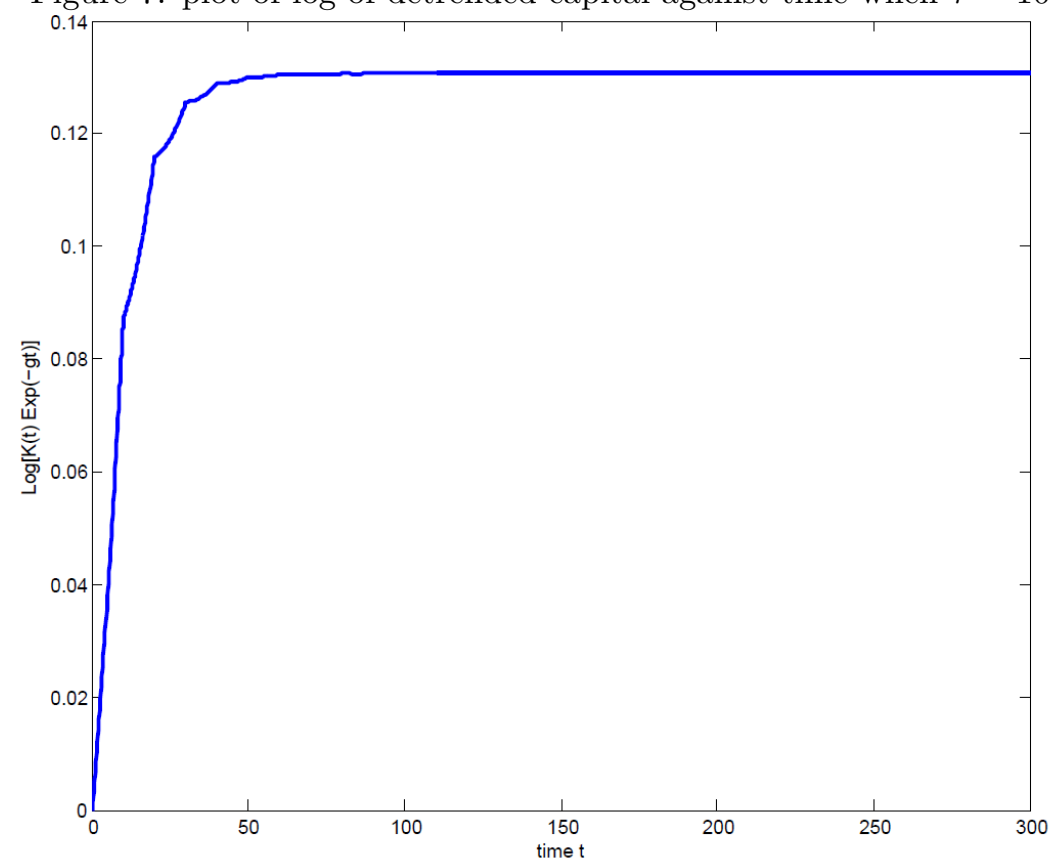

\section{Proposition B.1 (Growth Reversals for Large Delays)}

Suppose that the initial function of the detrended NDE associated to (3) is $x_{I}(t)=e^{\phi t}$ for $t \in[-\tau, 0]$ and some $\phi$ real. It follows that $\phi \dot{x}(0)<0$, hence convergence to the BGP is non-monotonic, if and only if:

$$
g>r+\frac{\phi}{e^{\phi \tau}-1}
$$

If $\phi \approx 0$, then condition (26) writes as:

$$
\tau(g-r)>1
$$

Proof: follows by adapting the proof of Proposition 3.3 in Boucekkine and Pintus [11]. Note that the initial growth rate of detrended capital $x$ relates to that of capital $K$ through $\phi=\mu-g$. Condition (27) can be viewed in a simple way as the fact that growth reversals occur only if the no-commitment delay is large enough (see Boucekkine and Pintus [11] for an intuitive discussion of why this is the case). We now provide examples that illustrate Proposition B.1. Figures 7 and 8 (based on table 2 and figures 3-5) picture the short-run dynamics ${ }^{16}$ of detrended capital $x$ for two economies that are similar in all respect except that $\tau=10$ for economy $\mathcal{A}$ and $\tau=70$ for economy $\mathcal{B}$. Economy $\mathcal{A}$ goes through negligible growth breaks (figure 7) whereas economy $\mathcal{B}$ experiences

\footnotetext{
${ }^{16}$ Figures 7 and 8 are produced using the MATLAB NDE solver provided by Shampine [39].
} 


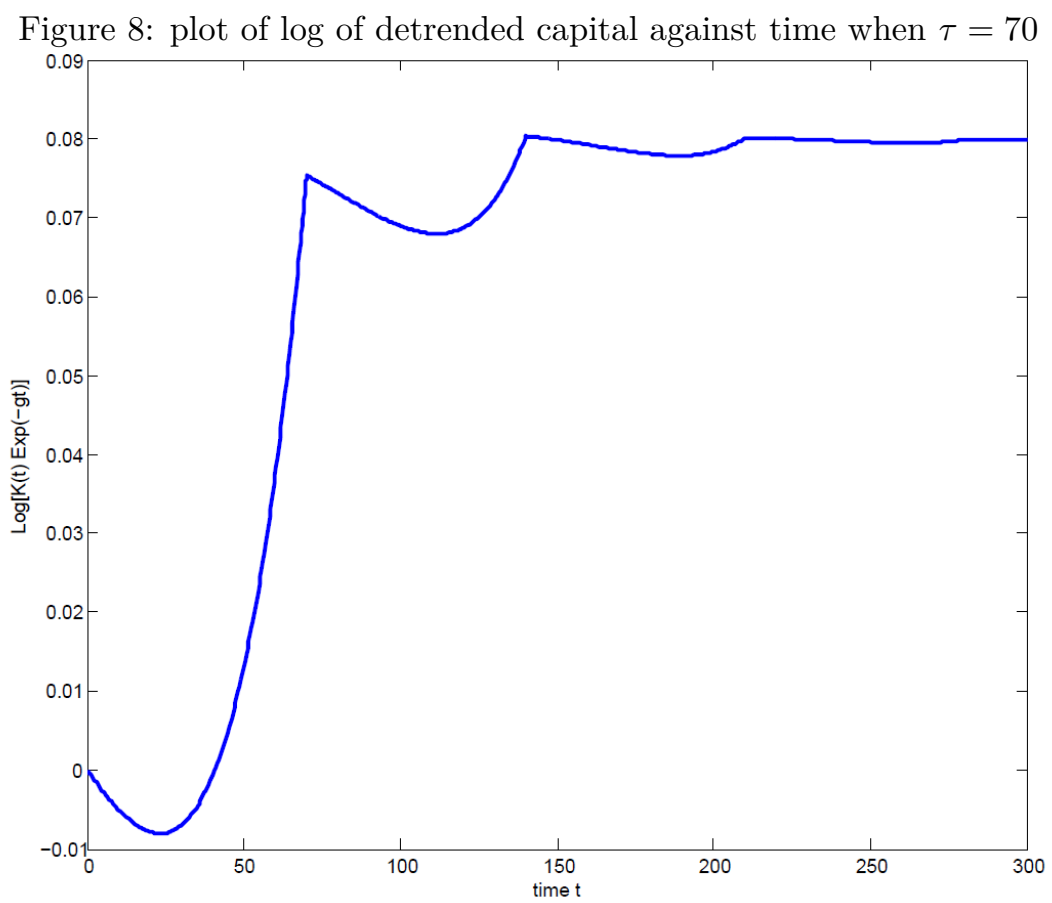

sharp growth reversals (figure 8). Because figure 8 plots $\log [x(t)]=\log \left[e^{-g t} K(t)\right]$, the kinks that appear at dates that are multiples of $\tau=70$ indicate growth reversals. For example, figure 8 assumes that the economy grows above the BGP level at $\mu=3 g$ so that the detrended growth rate $\phi=2 g$ is positive prior to $t=0$. Right after $t=0$, however, detrended capital declines, which indicates that the growth rate of $K$ is below the BGP level $g$ until $t \approx 25$, when the detrended growth rate becomes positive again. At $t=70$, a second growth reversal occurs and it leads to growth below trend until $t \approx 125$.

From table 2 , we know that $\mathcal{A}$ 's welfare is about $12 \%$ higher than $\mathcal{B}$ 's even though $\mathcal{B}$ 's initial consumption is about 11 percentage points larger than $\mathcal{A}$ 's. The higher welfare in $\mathcal{A}$ comes from the larger BGP growth rate (1.5\% vs $1.06 \%$ for $\mathcal{B}$; see table 2$)$. Such a difference in annualized growth rates means that while it takes 46 years to double consumption in $\mathcal{A}$, it takes 66 years in $\mathcal{B}$, that is, about one more generation. In addition, figures 6 and 7 tell us that $\mathcal{A}$ 's long-run output is about $5 \%$ higher than $\mathcal{B}$ 's. Therefore, growth reversals are associated with welfare losses because they require large no-commitment delays (that is, $\tau$ 's that are much larger than $\tau_{o p t}$ ).

It is worth stressing that welfare losses under growth reversals are not due to consumption volatility (as consumption jumps to the BGP at $t=0$ ) but rather because the negative growth effects dominates the positive level effect on consumption. Not surprisingly, higher $\sigma$ 's lead to smoother growth reversals, as expected because intertemporal substitution is then less strong. In 
addition, it is worth mentioning that the dynamics of detrended capital depicted in figures 7-8 is also that of the real exchange rate, defined as the price of non-tradeable good (labor, which is inelastic and normalized to one) in terms of the tradeable good (output), as the latter is proportional to capital in an $A K$ economy. This implies that growth reversals in capital are also associated with growth reversals in the real exchange rate. 